Florida International University FIU Digital Commons

3-10-1994

\title{
The use of aerobic exercise as an occupational therapy intervention for post traumatic stress disorder patients
}

Phyllis A. Davis

Florida International University

DOI: $10.25148 /$ etd.FI14062213

Follow this and additional works at: https://digitalcommons.fiu.edu/etd

Part of the Occupational Therapy Commons

\section{Recommended Citation}

Davis, Phyllis A., "The use of aerobic exercise as an occupational therapy intervention for post traumatic stress disorder patients" (1994). FIU Electronic Theses and Dissertations. 2746.

https://digitalcommons.fiu.edu/etd/2746

This work is brought to you for free and open access by the University Graduate School at FIU Digital Commons. It has been accepted for inclusion in FIU Electronic Theses and Dissertations by an authorized administrator of FIU Digital Commons. For more information, please contact dcc@fiu.edu. 


\section{FLORIDA INTERNATIONAL UNIVERSITY \\ Miami, Florida}

The Use of Aerobic Exercise as an Occupational Therapy Intervention for Post Traumatic Stress Disorder Patients

A thesis submitted in partial satisfaction of the requirements for the degree of Master of Science in Occupational Therapy

by

Phyllis A. Davis

1994 
To: William J. Keppler

\section{College of Health}

This thesis, written by Phyllis A. Davis, and entitled The Use of Aerobic Exercise as an Occupational Therapy Intervention for Post Traumatic Stress Disorder Patients, having been approved in respect to style and intellectual content, is referred to you for judgment.

We have read this thesis and recommend that it be approved.

Reba L. Anderson, Ph.D, OTR, FAOTA

Paulette M. Johnson, Ph.D

Patricia J. Scott, MPH, OTR

Major Professor

Date of Defense: March 10, 1994

The thesis of Phyllis A. Davis is approved.

Dean William J. Keppler

College of Health

Dr. Richard L. Campbell

Dean of Graduate Studies

Florida International University, 1994 
COPYRIGHT 1994 by Phyllis A. Davis

All rights reserved 
I dedicate this thesis to my parents for encouraging me to pursue a graduate education and to my fiance, for without his love, patience and understanding this thesis would not of been possible. 


\section{ACKNOWLEDGMENTS}

I would like to thank Dr. Gary Kutcher and Dr. Thomas Mellman for enabling me to do my thesis at the Veterans Affairs Hospital. Without their help and dedication, this thesis topic would not of been possible. I would also like to thank my committee members: Patricia Scott, Reba Anderson and Paulette Johnson for all their knowledge and helpful advice. 


\section{ABSTRACT OF THE THESIS Traumatic Stress Disorder Patients \\ by \\ Phyllis A. Davis \\ Florida International University, 1994 \\ Miami, Florida \\ Professor Patricia J. Scott, Major Professor}

The Use of Aerobic Exercise as an Occupational Therapy Intervention for Post

Post Traumatic Stress Disorder (PTSD) is a psychiatric diagnosis receiving increased attention. Occupational therapists are becoming more involved with this diagnosis, particularly with Vietnam Veterans in Veteran Affairs Hospitals. Aerobic exercise is a treatment which has not been explored with this population. Depression and anxiety are symptoms commonly associated with PTSD. This study sought to determine whether aerobic exercise would reduce overall PTSD symptomatology, including depression and anxiety. Three psychological inventories: The Penn Inventory for PTSD, The Beck Depression Inventory (BDI), and The Beck Anxiety Inventory (BAI) and one physiological inventory: The Queens Step Test for $\mathrm{VO}_{2}$ Max were given to eighteen subjects before and after a four week period. Ten subjects engaged in no exercise, and eight subjects participated in an aerobic exercise program. Results indicate that aerobic exercise has a significant effect on reducing depression and anxiety and a marginal effect on their overall symptomatology. 


\section{Table of Contents}

CHAPTER

PAGE

I. INTRODUCTION $\ldots \ldots \ldots \ldots \ldots \ldots \ldots \ldots \ldots \ldots \ldots \ldots \ldots \ldots$

II. LITERATURE REVIEW

Post Traumatic Stress Disorder $\ldots \ldots \ldots \ldots \ldots \ldots \ldots \ldots \ldots \ldots \ldots$

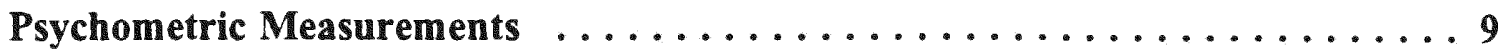

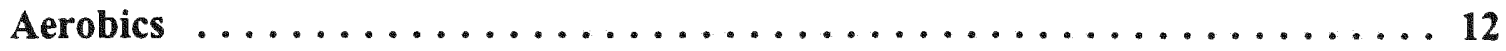

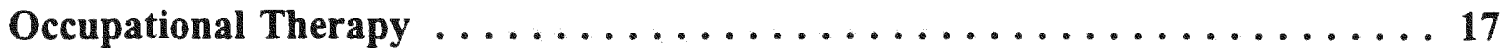

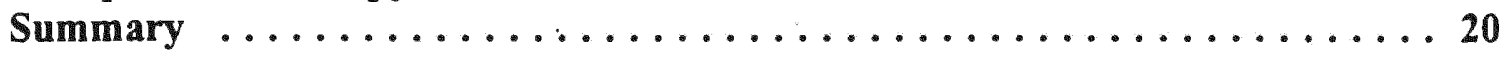

III. METHODOLOGY

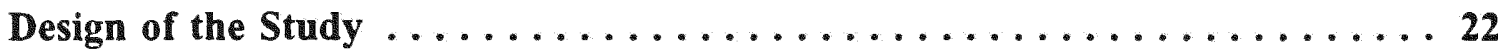

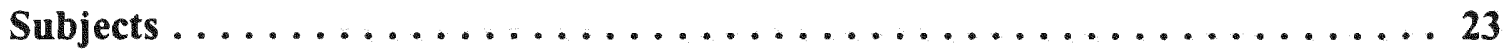

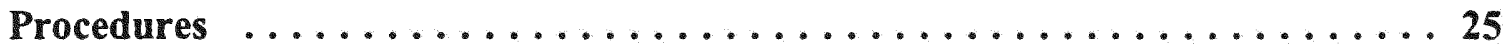

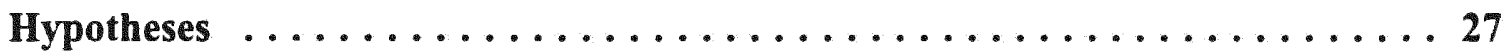

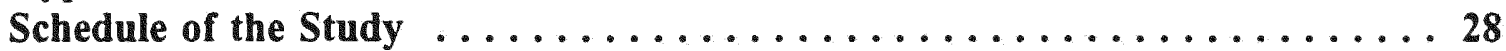

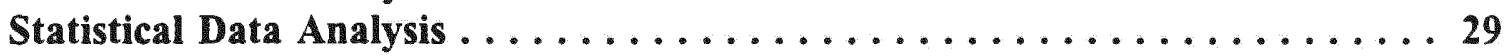

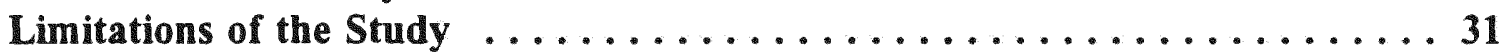

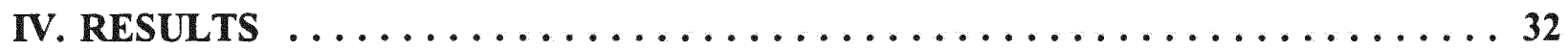

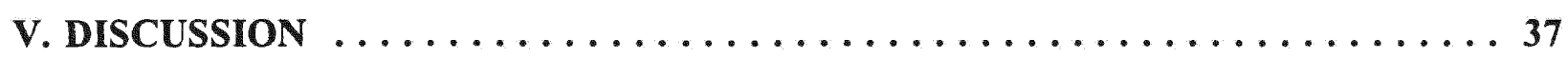

LIST OF REFERENCES $\ldots \ldots \ldots \ldots \ldots \ldots \ldots \ldots \ldots \ldots \ldots \ldots \ldots \ldots \ldots$

\section{APPENDICES}

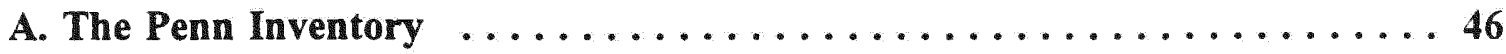

B. The Beck Anxiety Inventory $\ldots \ldots \ldots \ldots \ldots \ldots \ldots \ldots \ldots \ldots \ldots$

C. The Beck Depression Inventory .................... 51

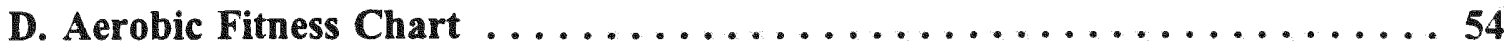

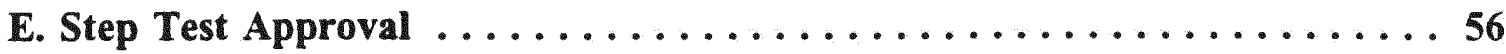

F. Step Test and Aerobic Exercise Approval . . . . . . . . . . . . 58

G. Informed Consent for Control Group ................. 60

H. Informed Consent for Experimental Group ............... 64

I. Diagnostic Criteria for Post Traumatic Stress Disorder ...........68 


\section{Chapter I - Introduction}

\section{Introduction}

Aerobic exercise has been widely used as a technique for improving psychological well-being. Much research has been conducted on the effect of aerobic exercise on depression, anxiety and other psychological disorders (Morgan \& Goldston, 1987; Doan \& Scherman, 1987; Folkins \& Sime, 1981). Currently, aerobic exercise is being used as part of numerous treatment intervention programs. Investigation into the literature on the treatment of Post Traumatic Stress Disorder (PTSD), however, indicates this is one area which has not yet adopted or included aerobic exercise as part of a therapeutic regime.

PTSD is classified as an anxiety disorder, which the Diagnostic and Statistical Manual of Mental Disorders (DSM III-R) states: "The essential feature of this disorder is the developing of characteristic symptoms following a psychologically distressing event that is outside the range of human experience" (DSM III-R, 1987). For the purposes of this paper, PTSD will be discussed and explored as it pertains only to individuals who are Vietnam Veterans who have been involved in combat.

Post Traumatic Stress Disorder is particularly difficult to treat and manage because of its varying symptoms, including anxiety, depression, sleep disturbances, and inability to concentrate. Aerobic exercise has, independent of the PTSD population, been found to have a positive impact on many of the symptoms of PTSD. An occupational therapy 
approach receiving increased attention is the use of aerobic exercise, both on an individual basis, and as a facet of overall wellness programs. Research into the application of aerobic exercise for patients with PTSD could be a stepping stone in the reduction of the overall symptomatology.

\section{Purpose of the Study}

The purpose of this study is to determine whether four weeks of supervised aerobic exercise reduces PTSD symptomatology in patients who are Vietnam Veterans. This study will reveal whether occupational therapy, through the use of aerobic exercise, can play a significant role in this specialized area of treatment. If aerobic exercise does, in fact, reduce PTSD symptomatology, then the inclusion of aerobic exercise in a comprehensive occupational therapy program is warranted.

\section{Statement of the Problem}

Approximately 15 percent of the 3.1 million Vietnam veterans in the United States suffer from PTSD (Kulka, Fairbank, Hough, Jordan, Marmar, \& Weiss, 1990). The large number of individuals afflicted with the disorder has resulted in much attention and research being focused in this area. No one treatment approach has as yet been pronounced as being effective for any length of time (Solomon, Gerrity, \& Muff, 1992). Therefore, different types of treatment are continuously being tested and implemented in order to reduce the symptomatology of PTSD. One method of treatment, which has not 
been tested until now, is the use and evaluation of aerobic exercise as a symptom remedy for the PTSD population. Occupational therapy is moving towards the active incorporation of exercise and wellness programs as part of an overall purposeful treatment activity. Therefore, an occupational therapy program is an appropriate vehicle for the implementation of this therapy with the PTSD population.

\section{Definitions}

In the literature, the terms "aerobic exercise" and "physical fitness" are often used interchangeably. Health related physical fitness is operationally defined as: "including cardiorespiratory endurance, body composition, muscular strength and endurance and flexibility. The concept that underlies health-related physical fitness is that better status in each of the constituent components is associated with lower risk for development of disease and/or functional disability" (American College of Sports Medicine, pg.8 1991). For purposes of this study aerobic exercise will be defined as: an activity that requires using large muscles, being involved in an activity for at least 15 continuous minutes, and is rhythmic in nature and is done at least three to five times per week (ASCM, 1991).

\section{Significance of the Study}

The existing literature does not reflect a cure for PTSD and current treatments are solely for symptom reduction. Aerobic exercise has been successfully used to reduce the effects of other psychological problems, but has not yet been explored as a treatment 
intervention for this population. In addition, the implementation of aerobic exercise as an integral part of PTSD treatment may provide a tremendous opportunity for the minimization of PTSD symptomatology, which could enhance the eventual functional independence of those afflicted with this disorder.

\section{Assumptions}

An implicit assumption of this study is that exercise is a socially accepted and appropriate activity in which participation would not be detrimental to those affected with PTSD.

A second assumption is that the relative change in $\mathrm{VO}_{2} \max$ will be greater in otherwise sedentary individuals than it will be in those patients which have previously engaged in regular, aerobic activity.

A third assumption is that aerobic exercise is only an effective intervention if the individual chooses to incorporate it into their lifestyle.

A fourth assumption is that reduction of PTSD symptomatology would permit a greater functional independence lifestyle of patients afflicted with this disorder. 


\section{Chapter II - Literature Review}

\section{Post Traumatic Stress Disorder}

Post-Traumatic Stress Disorder (PTSD) is a relatively new psychiatric diagnosis, first included in the Diagnostic and Statistical Manual III (DSM III). Classified as an anxiety disorder in 1980, the current DSM III-R diagnostic criteria includes: (1) exposure to an extreme stressor outside the range of usual human experience; (2) re-experiencing the traumatic event via memories, dreams, flashbacks, or distress at exposure to reminders; (3) persistent avoidance of stimuli associated with the trauma, or numbing of general responsiveness; and (4) symptoms of increased arousal, such as sleep disturbance, irritability, difficulty concentrating, hypervigilance, and exaggerated startle response.

Although PTSD was first formally classified in the DSM III in 1980, it has been observed and described for centuries. During the Civil War, terms such as: soldier's heart, combat neurosis, and shell shock were being used to describe a pattern of symptomatology corresponding to current views of PTSD (Keane, Wolfe, \& Taylor, 1987). It was not until World War I, that a specific clinical syndrome became associated with combat duty. Later, during WWII, Grinker and Spiegal (1945) offered specific psychiatric terminology to present a cohesive account of the symptom picture surrounding combat related PTSD (Keane, Wolfe, \& Taylor, 1987). Most recently, during the Vietnam War, "combat stress" became commonly referred to as PTSD. 
PTSD is difficult to treat because of the variety of symptoms. In addition, more and more people are being assigned the diagnosis. As a result, it has been suggested by Iacono (1984) and Peterson (1991), that depression and anxiety be moved from an associated feature to a primary feature of this disorder, specifically regarding Vietnam combat veterans. However, there has been great controversy in the literature as to whether or not PTSD is a disorder independent of an already existing diagnosis (Keane, Wolfe, \& Taylor, 1987). It has been observed that combat-related PTSD, particularly of the chronic nature, is frequently associated with other psychiatric disorders. This comorbidity has been well documented in both clinical and epidemiological data (Mellman, Randolph, Mintzer-Brawman, Flores, \& Milanes,1992). Due to the controversy in the literature over the validity of PTSD, as an independent disorder, many studies have been, and continue to be, conducted on the etiology, assessment and treatment for those suffering from PTSD.

\section{Types of Treatment}

Treatment for PTSD focuses on symptom management, because no single approach has been found to be completely effective in the treatment of the disorder. Many different therapeutic techniques are being researched and implemented. One recent treatment technique that has been growing in popularity is the inpatient program. Between 1978 and 1989, sixteen units were established at various Veteran Affairs (VA) facilities (Scurfield, Kenderline, \& Pollard, 1989). These programs typically use a milieu therapy 
approach and incorporate a variety of treatments to reduce the overall symptomatology of PTSD.

The most positive results of participation in an inpatient program lie in the areas of self-esteem enhancement, interpersonal relationships and self-awareness. The primary PTSD symptom improvements concerned numbing of general responsiveness and reduced arousal (Harmand, Starkey, \& Ashlock, 1987; Scurfield,Kenderline, \&Ashlock, 1989). Follow-up studies found, however, that without continuous treatment, even after a successful inpatient program, patients are not completely symptom free of the disorder. Therefore, an ongoing need exists for subsequent forms of therapy that extends past an inpatient stay. Aerobic exercise, if efficacious in reducing PTSD symptomatology could be a treatment technique which patients could continue on their own by integrating exercise into their daily lifestyle.

\section{Psychotherapies for PTSD}

Psychological therapies remain the primary treatment for PTSD, regardless of the use of medication, although medication does have a positive impact on psychotherapy (Bleich, Siegal, Garb, \& Lerer, 1986). It appears as if most forms of psychotherapy have been attempted in the treatment of this disorder, but few have been systematically tested to determine which one is best for this population. Therefore, depending on the resources and needs of the currently established programs, a variety of therapies are being utilized, 
with sparse research substantiating their effectiveness (Solomon, Gerrity, \& Muff, 1992).

Some examples of these psychological therapies include:

(1) Behavioral therapy applies learning principles in an attempt to eliminate the unwanted behavior. This techniques uses systematic desensitization, flooding, biofeedback, relaxation and stress management.

(2) Cognitive therapy focuses on teaching new, more adaptive ways of thinking and acting is based on the assumptions that thoughts intervene between events and our emotional reactions (Myers, 1986). Techniques include: thought stopping, muscle relaxation, communication skills, and guided self-dialogue.

(3) Hypnotherapy is defined as a temporary state of heightened suggestibility in which some subjects narrow their focus of attention and experience imaginary happenings as if they were real (Myers, 1986). This treatment allows a patient to release unconscious information and integrate the traumatic event. Because there is no single psychodynamic approach to understanding and treating PTSD, a number of complementary approaches can be utilized within a broadly conceived psychodynamic tradition (Fairbank \& Nicholson, 1987).

\section{Drug Therapy}

Another area of treatment is the use of pharmacological interventions. There have been five double blind, placebo controlled trials of drug therapies for PTSD (Solomon, 
Gerrity, \&. Muff, 1992). While overall, mixed results were found, it has generally been concluded that antidepressant drugs exert a beneficial effect on PTSD symptoms and do not work solely by their less specific antidepressant or antianxiety effects (Davidson \& Nemeroff, 1989). As a result, drug therapy has been recommended as a useful and complementary adjunct to psychotherapy.

\section{Psychometric Measurements}

Various psychometric properties are being developed and tested to obtain the most reliable and valid tools for determining PTSD. Some hold that the use of psychometric measures with structured interviews provides the most information for assessing PTSD (Keane, Wolfe, \& Taylor, 1987). Using psychometric tools provides advantageous information on the frequency, severity and intensity of the disorder. Currently, the Minnesota Multiphasic Personality Inventory (MMPI), depression and anxiety inventories and measurement tools that measure the overall PTSD symptomatology, such as the Mississippi Scale for Combat Related PTSD (M-PTSD), are among the most commonly used.

The Penn Inventory, one of the more recently developed tools for determining the severity of PTSD, is based on DSM III and DSM III-R criteria. The Penn format consists of 26 questions and models the Beck Depression Inventory. The Penn questions are multiple choice and each question is scaled from $0-3$ points, and provides a continuous 
total scoring from 0-78. Each question measures the presence or absence of PTSD including degree, frequency, and intensity. This inventory takes approximately ten minutes, per subject, to complete (Hammarberg, 1992)(see Appendix A).

The measure of internal consistency for the Penn Inventory was .94 across all subjects, .86 for those in treatment, and .94 for those in post- treatment. Test-retest reliability was .96 with $\mathrm{p}<.0001$ for all subjects, .89 for those in treatment, and .87 for those in post- treatment. The average for each item's test-retest reliability was .78 , with a range of .58 to .87 , and $\mathrm{p}<.0001$.

Many psychological measurement tools have been used to assess the degree of depression and anxiety in subject populations. There does not appear to be one specific inventory that is most commonly used. Examples of frequently used depression inventories are: The Beck Depression Inventory (Harden \& Allen, 1984; Rape, 1987), The Zung Self Rating Depression Scale (Brown, Remarries \& Tab, 1978; Hannaford et al, 1988) and The Symptom Check List (Klein et al, 1985; Griest et al, 1979) Examples of frequently used anxiety measures include: The Taylor Manifest Anxiety Scale (Hammer \& Wilmore, 1973), and the Spielberger State-Trait Anxiety Inventory (Maloney et al, 1986; Long \& Haney, 1988).

The Beck Anxiety Inventory, (BAI) is a 21 item scale that measures the severity of anxiety in adults and adolescents. The questions consist of descriptive statements of 
anxiety symptoms in which responses are rated on a four-point scale with the total test scores ranging from 0 to 63 . The BAI may be scored and administered by paraprofessionals, but should be interpreted by professionals with clinical training. The test is usually completed within a five to ten minute period. Test reliability and internal consistency $=.92$, test-retest (the correlation between intake and one-week BAI scores) $=.75(\mathrm{p}<.001)$. Validity (correlated with the Trait $(r=.58, \mathrm{p}<.001)$ and State $(r=.47$, $\mathrm{p}<.01)$ subscales for the State Trait Anxiety Inventory Form Y (Beck, 1988)(see Appendix B).

The Beck Depression Inventory, (BDI) is a 21 item scale that measures the severity of depression. Each statement consists of four to six statements, rank-ordered to assess a single behavior or symptom aspect of depression. The scores can range from 0 63 and are generally completed in five to ten minutes. Subjects are instructed to respond in terms of how they feel "today, that is right now (Beck, 1987) (see Appendix C). The Beck Depression Inventory does not address reliablity, but does provide statistical data on stability. The stability correlation between pre-test and post-test mean was $.60-.90$. Internal consistency was found to be .86 . A concurrent mean correlation of .72 was found between clinical ratings of depression and BDI scores on psychiatric patients (Beck, 1987). In a correlation analysis, it was found that among those diagnosed with PTSD, the Beck Depression Inventory and Beck Anxiety Inventory were positively correlated with 
the Penn Inventory, $\mathrm{r}=.84, \mathrm{r}=.56, \mathrm{n}=52$, both $\mathrm{ps}^{<.0001}$. These findings support the common observation that depression and anxiety are regular accompaniments of PTSD.

\section{Aerobics}

"Aerobics" became a popular exercise method after Dr. Kenneth Cooper, a cardiologist, published a book in 1968 on the cardiovascular benefits of aerobic activity. This book launched the fitness boom and convinced people that exercising can help to improve physical health and longevity. Cooper defines aerobics as "a variety of exercises that stimulate heart and lung activity for a time period sufficiently long to produce beneficial changes in the body" (Cooper, 1970 p.15) and "those activities that require oxygen for prolonged periods and place such demands on the body that it's required to improve its capacity to handle oxygen" (Cooper, 1982 p.13). Aerobic fitness is any activity that, (1) uses large muscle groups, (2) can be maintained continuously, and (3) is rhythmic in nature. Virtually all evidence in the literature indicates that improvement in aerobic fitness is directly related to the intensity, frequency and duration. The American College of Sports Medicine publishes an aerobic fitness protocol that should be followed when designing aerobic programs.

These guidelines state that: the exercises should consist of any of the recommended large muscle groups, be a rhythmic activity (ie, walking, running, 
swimming) and be performed three to five days per week at $60-70$ percent of maximum heart rate for a minimum of 15-60 minutes of continuous aerobic activity.

\section{$\underline{\text { Studies and Methodological Issues }}$}

Many studies have been conducted on the physical and psychological problems associated with PTSD, including: depression, anxiety, stress, self-concept, sleep disorder and concentration difficulty. These studies have produced positive results, indicating that aerobic activity can, in fact, reduce these symptoms (Folkins \& Sime, 1981; Physician and Sports Medicine, 1992). However, for the purposes of this review, the psychopathological symptoms of PTSD will be limited to anxiety and depression.

The first aerobic exercise study as a treatment for depression was performed in 1979 by Griest, Klein, Eishens, Faris, Gurman, \& Morgan. In just over ten years, over 1000 articles have been written on the psychological effects of exercise including: anxiety, depression, self-esteem, cognition, etc., (Hughes, 1984). There is a widespread agreement and general societal belief that aerobic exercise can have a positive influence on psychological well-being. However, many of the studies that have performed thus far suffer from methodological problems. These problems include: studies being performed on normal populations and the findings being generalized to clinical populations; poor controls of the initial cardiovascular fitness level of the subjects; poor choice of psychological constructs; no control group; no standardized exercise guidelines; 
experimenter-subject biases; and inadequate description of methods (Hughes, 1984, Simons, McGowan, Epstein, \& Kupfer 1985; Doan \& Scherman, 1987; Brown, 1987; Boutcher, 1990). Because of these limitations, many of the studies performed cannot be replicated nor the findings viewed as statistically valid.

More recent studies, however, have been performed using specific procedures and standardized protocols (Doyne, Ossip-Klein, Bowman, Osborn, McDougall-Wilson, \& Neimeyer, 1987; Hannaford, Harrell, \& Cox, 1988; Klein, Griest, Gurman, Neimeyer, Lesser, Bushnell, \& Smith,1985; McCann \& Holmes, 1984; Blumenthal, Emery, Madden, George, Coleman, Riddle, Mckee, Reasoner, \& Williams, 1989). The results of these studies can be used to make assumptions and to draw conclusions as to the use of aerobic exercise with different psychopathologies. Based on this recent research, it can be concluded that anxiety and depression can be treated using aerobic exercise and that aerobic activity may be as effective a technique as are the psychotherapies (Simons et al, 1985; Hales \& Travis, 1987). No one form of aerobic activity was found to be superior to another, and most of these studies used walking, jogging or swimming as their main primary technique. One critical factor that was noted from this research is that each subject's heart rate must reach aerobic capacity for conclusions to be drawn. 


\section{Cardiovascular Measurement}

Another area of concern with the implementation of aerobic fitness studies is that of cardiovascular measurement, otherwise known as $\mathrm{VO}_{2} \max$. While there are many ways to determine aerobic fitness, the most accurate method is direct assessment. However, direct assessment requires an extensive laboratory, expensive equipment and is an extremely time consuming process. With indirect assessment the subjects do not have to work to exhaustion and therefore, are not subject to risk. There are other types of tests that can be used to predict fitness levels, but because they are less accurate, these techniques are termed submaximal tests or indirect methods. Since they are inexpensive, easily administered, and equipment non-intensive, several studies have made use of indirect methods (Maloney, Cheney, Spring \& Kanusky, 1986; Buchanan, Sallis, Criqui, Dimsdale, \& Kaplan, 1991 and Goldwater \& Collins, 1985). Submaximal testing is not appropriate for all populations but can be used effectively in the proper setting. The ACSM confirms, the general accuracy of the predicted $\mathrm{VO}_{2}$ max values from submaximal tests, although far from perfect for diagnostic purposes in individual cases, are still acceptable for pre and post measures of group fitness. Through their studies and research, Thompson and Martin (1984) recommend the use of highly correlated submaximal tests, such as the Queens College Step Test and the Harvard Step Test. 


\section{Biochemical Effects}

It has been hypothesized that biochemical effects of aerobic exercise act similarly to some medications used with the PTSD population. It has been suggested that strenuous aerobic exercise may have a biochemical effect on the production of norepinephrine, serotonin, or dopamine in the human body. Although several experts believe that there may be a connection between aerobic exercise and the production of these agents, further research needs to be conducted. Additionally, before the validity of these theories can be confirmed the question of whether habitual exercise enhances the transmission of these neurotransmitters is also unknown (Hughes, 1984).

Aerobic exercise has been implicated as a technique to lessen the need for antidepressant drug use. Studies on depressed patients revealed that aerobic exercises are as useful as different forms of psychotherapy and that exercise produces an antidepressant effect on patients with depression. (Physician and Sports Medicine, 1992; Hales \& Travis, 1987; Hannaford, Harrel \& Cox, 1988; Martinsen, Hoffart \& Solberg, 1989; Folkins \& Sime, 1981). Further studies have proven that this antidepressant outcome occurs within the first few weeks of exercise as a treatment (Fremont \& Craighead, 1984; Sime, 1984; McCann \& Holmes, 1984). Since PTSD patients are commonly given antidepressant drugs, a reduction in medication would make more cost effective treatment, if aerobic exercise could produce the similar reductions in symptomatology as prescribed medication, there may be further justification to implement aerobic exercise as part of occupational therapy. 


\section{Exercise and Lifestyle}

Because research has found aerobic exercise to be positively correlated with psychological improvement, the National Institute of Mental Health (NIMH) reviewed the potential psychological benefits of being involved in a regular physical activity, including aerobic activities. The objective is for health professionals to encourage the use of exercise as part of an individual's lifestyle. The findings of the NIMH research are: (1) exercise can be associated with reduced state anxiety; (2) exercise can be associated with a decrease in mild to moderate depression; (3) long- term exercise is usually associated with reductions of neuroticism and anxiety; (4) exercise may be an adjunct to the professional treatment of depression, (5) exercise can result in the reduction of various stress indices, and (6) exercise can have beneficial effects across all ages for both sexes (Morgan \& Goldston, 1987). From these findings it would be highly recommended for PTSD suffers to incorporate aerobic exercise as part of their daily activities.

\section{Occupational Therapy}

The literature relevant to this study includes the use of aerobic exercise as occupational therapy for individual symptoms of PTSD (ie: anxiety, depression, stress), without specifically involving the PTSD population. Until recently, the literature did not reflect the use of aerobic exercise in occupational therapy. However, aerobic exercise is widely considered to be a purposeful activity, thought to be the core of the occupational therapy therapeutic process (Ludwig, 1988). 
Gail Fidler's theoretical perspective on purposeful activity holds that "An activity is purposeful only if it is congruent with 'the individual's sensory, motor, cognitive psychological and social maturation...and recognized by [the individual's] social and cultural groups as relevant to their values and needs (Fidler, 1983)." Further, doing can be described as performing, producing or causing purposeful action in order to: test a skill, clarify a relationship or create an end product (Fidler \& Fidler, 1978). Occupational therapists incorporate "doing" to enable patients to maximize their functional independence.

Following Fidler's theory, the justification for using aerobic exercise as an occupational therapy activity with the PTSD population, becomes clear. Activity analysis is the main component of Fidler's work. Fidler believes that activities should be chosen to match the patient's needs and that the performance of each activity should be controlled and guided to maximize its therapeutic value. In addition, activities should include: motor, sensory, integrative, psychological, socio-cultural, cognitive and interpersonal skills.

Fidler and Fidler (1983) believe that the more masteries one has, the stronger one's sense of competency will be. Fidler views competence, mastery, self-esteem, self-value, and self- worth as interrelated states which are derived from direct encounters with, and successful management of, elements in the environment. It is important that occupational therapists utilize activities which are accepted by society and viewed as significant and 
meaningful. In the absence of this, patients could experience negative reinforcement, potentially impacting their self-worth and confidence.

\section{Health and Illness}

Fidler (1983) describes "health" as: "the ability to perform those roles and tasks of living, throughout the lifecycle, that are essential to care for and to maintain the self in an individual manner, satisfy one's personal needs... (p. 30)." Dysfunction occurs when daily living skills for self-maintenance, work and leisure are interrupted or impaired.

Occupational therapists have an ongoing responsibility to adapt and alter practice to meet the needs of patient populations and the health care system. "Understanding that change is inevitable, knowing that services shift to meet changing consumers needs, and effectively designing and developing suitable programs that address social changes are skills that enabled occupational therapists to become change agents" (Gibson, 1992, p.268). Currently, occupational therapy uses a holistic approach that emphasizes mind/body unity. Gibson (1992) states that: "regular physical exercise and recreational opportunities are needed to complete the holistic rehabilitation program" (p.268).

Although occupational therapists are cognizant of the fact that there are many treatment options, the use of purposeful activity is, without question, the intervention of choice (Fidler, 1991). The principal focus of occupational therapy is maximizing the healthy aspects of the patient, while trying to minimize the pathology or disorder. If 
proven effective, aerobic exercise could become a beneficial activity incorporated into occupational therapy sessions.

Another approach that uses exercise as an occupational therapy option is that of stress management. In 1983, at the University of Texas Medical Branch at Galveston, Texas, an adult psychiatric occupational therapy inpatient program incorporated a stress management concept into the existing program. An exercise therapy group was one of the five treatment techniques. This treatment consisted of a progressive walking, jogging, or running program that met five times each week for 45 minutes per session. A standardized anxiety scale, was administered to assess the improvements in subjects' anxiety level. This program is still being used with much success. Charlesworth and Nathan (1984) stated that, " exercise provided a way of releasing muscle tension and general physical arousal accumulated in the response to stress.

\section{Summary}

Impressions from the literature suggest that, the experts in the field of PTSD expect anxiety and depression to become a primary symptom in the updated DSM IV. It is further believed that PTSD may ultimately become more commonplace than other, more prevalent psychological disorders, including depression (Solomon, Gerrity, \& Muff, 1992). At this point treatment of PTSD is aimed at symptom reduction. One form of treatment that has been frequently used, and has successfully treated the symptomatology 
of numerous psychopathologies, including depression and anxiety, is the use of aerobic exercise. Due to the prevalence of PTSD and the current trend toward utilizing aerobic exercise for the improvement of depression and anxiety, the efficacy of using this technique to reduce symptoms in PTSD needs to be explored. If found to be a valid approach then occupational therapists will inevitably become involved in the treatment of patients who demonstrate PTSD symptomatology through the use of aerobic exercise and wellness programs. 


\section{Chapter III - Methodology}

\section{Design of the Study}

A two-group pre-post test design was used for this study. The independent variable was the level of aerobic exercise, while the dependent variables were the Step Test, PTSD symptomatology, (anxiety and depression levels of the participants), as measured by items on the Penn Inventory for PTSD, The Beck Anxiety Inventory (BAI) and The Beck Depression Inventory (BDI).

Control Group $=\quad 0_{1} \quad 0_{2}$

$\begin{array}{llll}\text { Experimental Group }= & 0_{3} & X & 0_{4}\end{array}$

$0_{1}=$ pre-test on Step Test, Penn Inventory, BDI and BAI.

$\mathrm{O}_{2}=$ post-test on Step Test, Penn Inventory, BDI and BAI.

$0_{3}=$ same as $0_{1}$

$\mathrm{X}=$ aerobic exercise for a four week period, 3 times per week for at least 15 minutes, continuously.

$\mathrm{O}_{4}=$ same as $\mathrm{O}_{2}$

The following information was obtained for each subject:

-Age

-Sex

-Education completed

-Employment status

- Martial status

-If this is the first program for PTSD treatment

Each subject began the study one week after admission into the inpatient VA program. 


\section{Physiological Variables}

The Queens Step Test, (McCardle, 1991), a submaximal test was used for this study. Procedures for the test are as follows: A 16.1/4 inch high bench was used and one person was tested at a time for a three minute period. Each stepping cycle was performed to a four step cadence, following a four beat metromone, ("up-up-downdown"). The test began after a brief demonstration and practice period. At the completion of stepping, the subject remained standing, and a pulse rate was measured for a 15 second period after five seconds of recovery. Recovery heart rate was converted to beats per minute ( $15 \mathrm{sec}$ HR $\times 4$ ). To predict the VO2 max for males for the step test the following equation was used:

Men $=\max V O 2=111.33-(0.42 \times$ step test pulse rate, beats per minute $)$.

One can be 95 percent confident that the predicted VO2 max will be within $+/-16$ percent of the person's true $\mathrm{VO}_{2} \max (\mathrm{McCardle}, 1991)$.

\section{Subjects}

The subjects who participated in this study are Vietnam veterans diagnosed with PTSD. Participants were drawn from a three-month, inpatient treatment program for PTSD at the Miami Veterans Affairs Hospital in Miami, Florida. All eligible participants meeting selection criteria were involved. There were eighteen subjects total, ten subjects in the control group and eight subjects in the experimental group (aerobic exercise group). The selected subjects aged from $42-57$. 


\section{Inclusionary Criteria:}

(1) Veterans Diagnosed with PTSD.

(2) Enrollment in the PTSD inpatient program.

(3) Subjects must read and sign a consent form (see Appendix G, H).

(4) Subjects must receive a physician's approval prior to participation (see Appendix E, F).

(5) Subjects must agree to exercise.

\section{Exclusionary Criteria:}

(1) Any condition where aerobic exercise is not possible or is contraindicated.

(2) Subject will not sign a consent form.

(3) Subject leaves or is discharged from the PTSD program or subject does not comply with the aerobic exercise program.

(4) Any significant changes in medication will result in the subject being dropped from the study.

\section{Data Collection Techniques}

All data were collected by the researcher and the psychological tests were scored by a psychologist (BDI, BAI and Penn Inventory). The researcher administered and scored the Step Test. The results from the three psychological tests and the Step Test were maintained on individual charts and data were entered into a computer for analysis. 


\section{Procedure}

The researcher was introduced by the unit psychologist to each group and an explanation of the study was provided by the researcher. After the study was explained, permission to participate in the study was requested from each subject. In addition, the researcher explained that by signing the informed consent (Appendix $G, H$ ) each agreed to participate in this research to study the effects of aerobic exercise as an activity used in occupational therapy.

This study was conducted over a sixteen week period. The control group data were collected during weeks one through four. Control group data was collected from a different patient group, prior to the implementation of the aerobic exercise study. There was a subsequent eight week waiting period before the experimental group received the aerobic exercise as treatment. The four week treatment period was conducted during weeks thirteen through sixteen. Due to the nature of the setting, and the constant interaction among subjects, and a small patient population this waiting period was necessary. The control group performed the Step Test on the first and last day of the four-week time period, and also completed the Penn Inventory for PTSD, the BDI and BAI. 
The aerobic exercise group (the treatment group) performed the Step Test on the first and last days of the four-week time period. They also completed the Penn Inventory for PTSD, the BDI and the BAI, which were administered by the unit psychologist. In addition, this group exercised to meet ACSM guidelines for intensity (60-70 percent of estimated maximum heart rate), frequency (three times per week), and duration (15-60 minutes of continuous aerobic exercise). Each exercise session consisted of a five to ten minute stretching period, followed by 15-60 minutes of aerobic activity. The choice of aerobic activity included the following: walking, stair climbing, jogging, and jumping jacks. Each session concluded with a five to ten minute cool down period. To ensure the proper intensity of exercise, each subject in the exercise group was taught to monitor his heart rate and was required to maintain it at $60-70 \%$ of their target heart rate. The levels were determined following the American Heart Association formula for computing heart range (American Heart Association, 1975). This formula is as follows:

$$
(220-\text { AGE }) \times \text { RATE }=\text { BPM }
$$

\section{Where:}

\begin{tabular}{|c|c|}
\hline $\mathbf{A G E}=$ & The subject's age in years \\
\hline $\mathrm{RATE}=$ & $\begin{array}{l}\text { The subject's target heart rate (between } 60 \text { and } 70 \% \text { of } \\
\text { capacity) }\end{array}$ \\
\hline $\mathbf{B P M}=$ & The subject's heartbeats per minute. \\
\hline
\end{tabular}

In addition, the researcher accompanied the subjects during each exercise session and periodically performed spot checks to ensure that the subjects were exercising at their target heart rate. The subjects were also required to fill in individualized charts after the completion of each exercise session. Sections of this chart included: the type of exercise performed, the duration of exercise, and the heart rate achieved during the aerobic 
activity. These charts were kept on the inside of the subject's door for privacy, during the four-week study (see Appendix D).

\section{Hypotheses}

The research seeks to answer the question, "Does aerobic exercise, as an occupational therapy intervention, help reduce the symptomatology in Vietnam Veterans diagnosed with Post Traumatic Stress Disorder?"

Ho: There is no difference between the two groups', control and experimental, PTSD symptomatology as measured from pre to post by the three psychological inventories (Penn Inventory for PTSD, Beck Anxiety Inventory and Beck Depression Inventory) and no difference in aerobic capacity as measured by the Step Test.

The alternate hypotheses to be explored by this research include:

$\mathrm{H}_{1}$ : $\quad$ Following four weeks of aerobic exercise, aerobic capacity (VO2) max will increase in the experimental group as measured by the Step Test.

$\mathbf{H}_{2}$ : Following four weeks of aerobic exercise, the severity of PTSD will be reduced in the experimental group as measured by the Penn Inventory for PTSD. 
$\mathbf{H}_{3}$ : Following four weeks of aerobic exercise, depression will be reduced in the experimental group as measured by the Beck Depression Inventory.

$\mathbf{H}_{4}$ : Following four weeks of aerobic exercise, anxiety will be reduced in the experimental group as measured by the Beck Anxiety Inventory.

\section{Schedule of Study}

Each group followed a 28 day schedule.

Control Group- Day 1 Subjects performed Step Test and psychological inventories for base line data.

Day 28 Subjects performed Step Test and psychological inventories for post-test results.

Experimental Group- Day 1 Subjects performed Step Test and psychological inventories for base line data.

Day 2 Subjects exercise continuously for at least 15 minutes, not including a five to ten minute warm-up and five to ten minute cool down. Subjects chose either walking, jogging, or stair-climbing. Subjects monitored their heart rate and the researcher performed spot checks. 
Days $3,5,8,9,11,15,16,18,22,23,25$ Same as day 2 .

Day 28 Subjects performed Step Test and psychological inventories for post-test results.

\section{Statistical Data Analysis}

The data were analyzed using SAS computer software.

1. Demographic information was analyzed using t-tests and Chi-Square tests, depending on the type of variable. A Chi-Square test was performed on the question: "Is this program your first inpatient admission to a PTSD treatment program?"

2. Independent sample t-tests were performed on the pre-tests for the four measures; Step Test, Penn Inventory for PTSD, the BDI and the BAI to determine whether the two groups were at the same level at the beginning of the experiment.

3. Paired t-tests were conducted for each group, from pre-test to post-test on each variable to determine any significant change in the subjects' mean test results within each group. 
4. Independent sample t-tests were performed to determine if there was a difference between groups on the mean change in scores for each of the four tests.

\section{Adherence to Procedures}

Eight of the ten subjects in the control group performed the Step Test and completed the three psychological inventories on day one and on day 28. Two control group subjects entered the project two weeks late but completed the Step Test and the three psychological inventories with the four week interval between pre and post test.

All eight subjects in the experimental group performed the Step Test and the three psychological inventories on day one and day 28. Two subjects each missed one day of exercise, but exercised on their own to make up for the missed scheduled exercise session. During the three days per week of scheduled exercise each subject exercised at their target heart rate or greater but within their maximum limits. The duration of exercise increased during each session. At the end of the four weeks, the warm up period lasted ten minutes, aerobic exercise consisted of $35-40$, minutes and the session concluded with a ten minute cool down period. In addition, all subjects kept a record of the type of exercise they performed, the length of time they exercised, and their heart rate (see Appendix D ). 


\section{Limitations of the Study}

1. Due to a small sample size and a short time frame in which to conduct the study, statistically significant findings are difficult to achieve on the Step Test.

2. Collecting the control group data, over a different time period than that of the exercise group, may have introduced unexpected or uncontrollable factors into the study, such as history bias. This occurrence could of confounded the results and influenced the responsiveness of PTSD symptomatology to aerobic exercise.

3. The change found in the anxiety and depression may have been effected by the researcher's presence during the experimental group's activities rather than a direct result of the aerobic exercise treatment itself. 


\section{Chapter IV - Results}

Two groups were involved in a pre-test/post-test design study over a four week period. A statistical analysis was performed to determine equivalence among groups on age, years of education, current marital status, employment status and prior PTSD treatment. Using t-tests, no significant differences were found among the two groups $(p>.05)$. The mean age of the control group was $45.5(\mathrm{sd}=4.4)$ and of the experimental group was 47.8 ( $\mathrm{sd}=2.4$ ). The mean number of years of education for the control group was $12.9(\mathrm{sd}=2.2)$ and for the experimental group was $12.5(\mathrm{sd}=2.3)$. Using chi square tests, no statistical differences were found among the groups with respect to marital status. In the control group, 20 percent of the subjects were married, and in the experimental group, 12.5 percent of the subjects were married ( $>$.05). No statistically significant differences were found with respect to employment status. Thirty percent of the control group subjects were employed before entering the PTSD program and 25 percent of the subjects in the experimental group were employed prior to entering the program ( $>$ >05). Additionally, there was not a statistically significant difference found with respect to prior PTSD treatment. Twenty percent of the control group subjects had undergone prior PTSD treatment, and 25 percent of the experimental group subjects had undergone treatment (p>.05), see Table 1 . 
Table 1

Demographic Data for Subjects *

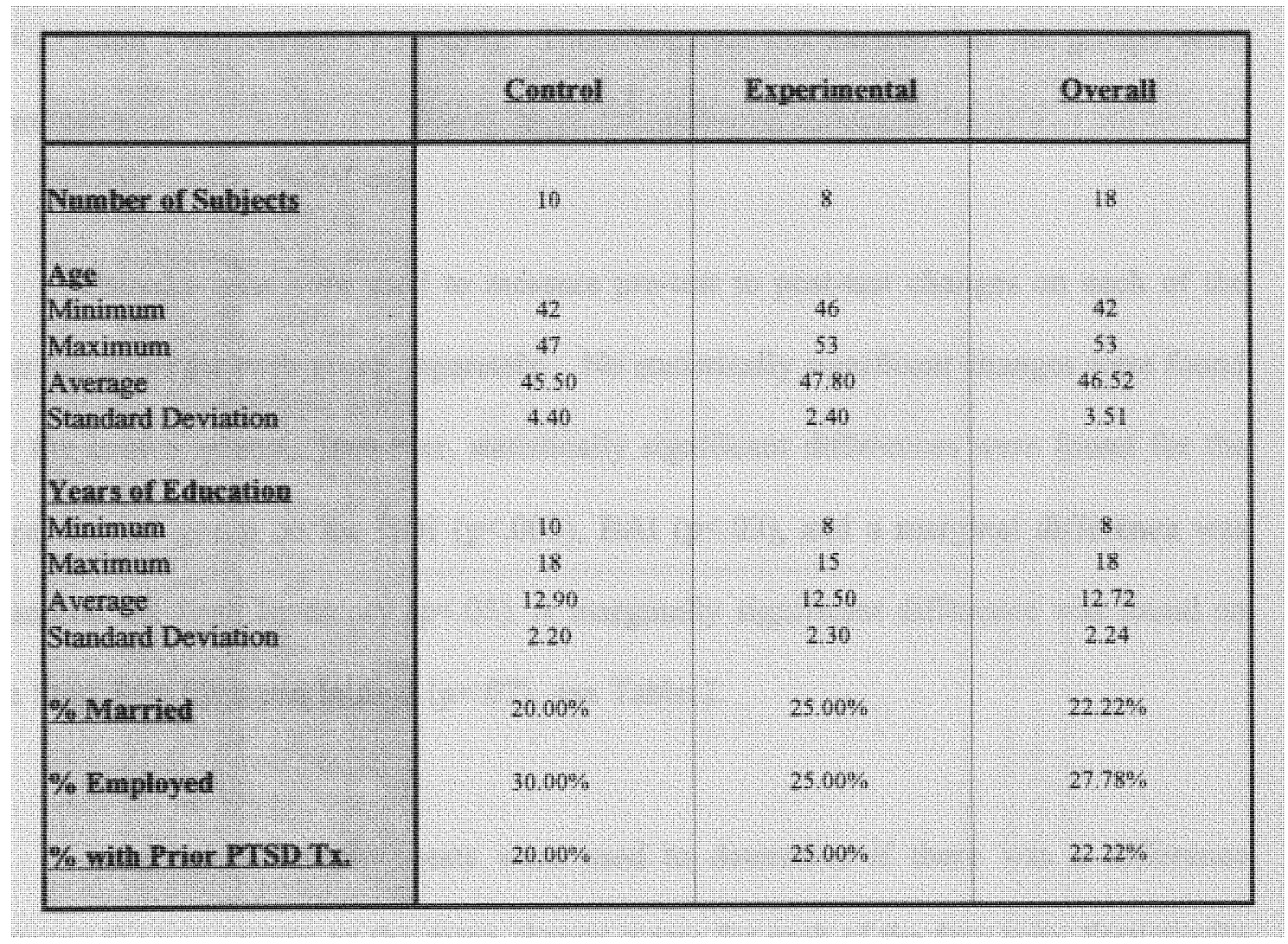

- There is no statistically significant difference between the two groups, $p>05$, on any of the demographic variables. 
Independent sample t-tests were performed on the two groups on each of the four measures: (Step Test, BDI, BAI, and Penn Inventory) to determine equivalence of the two groups. No significant differences were found on the pre-tests at the 5 percent significance level for any of the four variables: Step Test $(p<.22)$, BDI $(p<.40)$, BAI $(\mathrm{p}<.11)$ and Penn Inventory $(\mathrm{p}<.59)$. Therefore, one can assume that the groups were homogeneous.

Paired t-tests were used to measure pre-test to post-test changes on each of the four variables for each group separately. No statistically significant changes were found for the control group. However, statistically significant differences were found for the experimental group on the BDI $(p<.003)$, BAI $(p<.03)$, and a marginal difference was found on the Penn Inventory $(\mathrm{p}<.05)$. A marginally significant difference was found on the Step Test from pre to post $(\mathrm{p}<.07)$, see Table 2 .

Independent sample t-tests were used to determine if there was a difference between the two groups on the mean change scores for each of the four tests. Statistically significant differences were found between groups on the BDI $(p<.03)$, and on the BAI $(p<.02)$. No significant differences were found on the Step Test $(p<1.00)$, but a marginally significant difference was found between groups on the Penn Inventory $(\mathrm{p}<.08)$. 


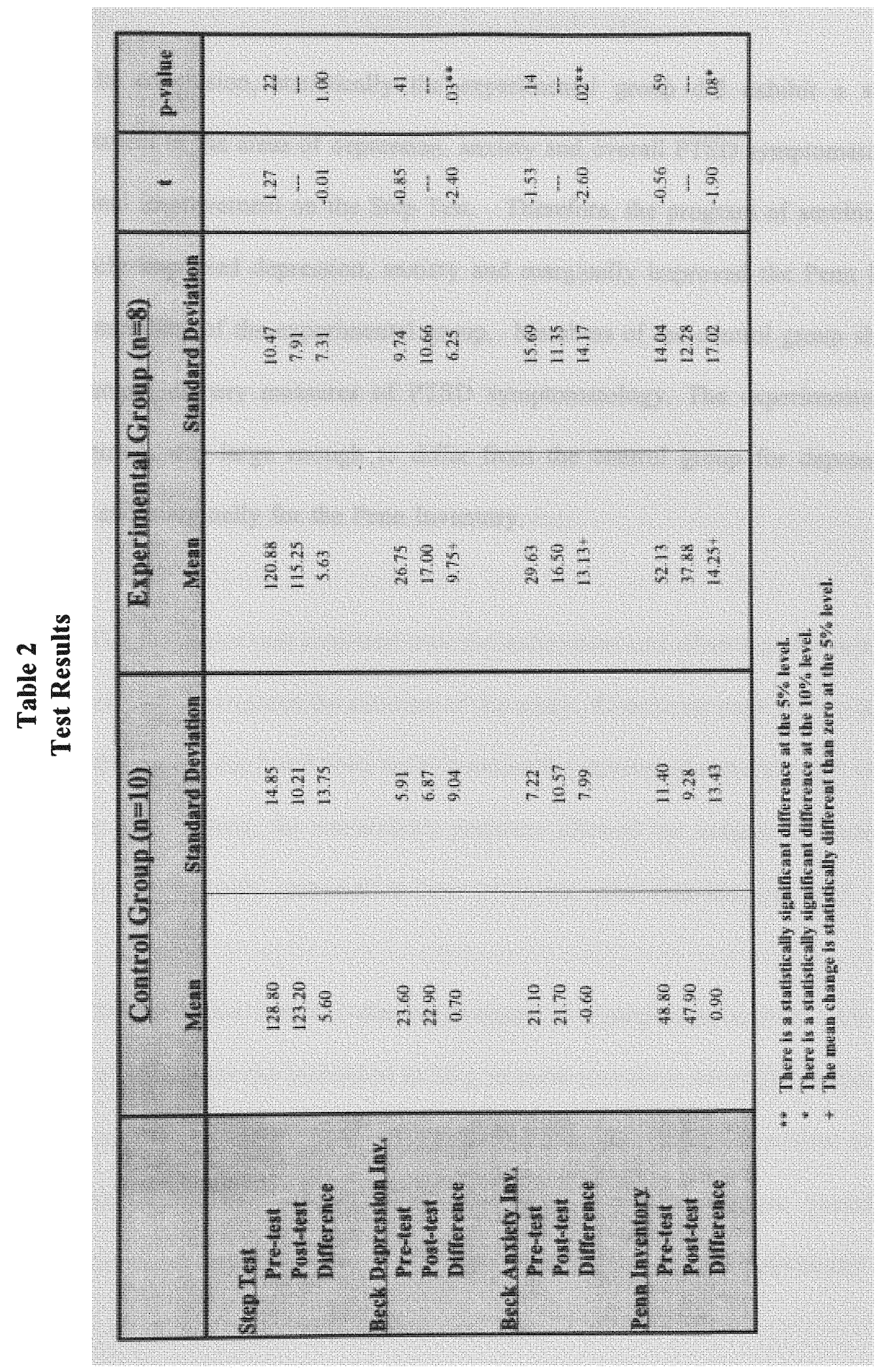


In conclusion, statistically the experimental group did exhibit a significant improvement in the areas of depression, anxiety and overall PTSD symptomatology and a marginal improvement on the Step Test. Therefore, the program of aerobic exercise effectively improved depression, anxiety and marginally improved the Penn Inventory among members of the experimental group. Members of the control group showed no improvement on any measures of PTSD symptomatology. The experimental group's improvement was large enough to differ from the control group for depression, and anxiety and marginally for the Penn Inventory. 


\section{Chapter V - Discussion}

Having the opportunity to work with Vietnam Veterans who have been diagnosed with PTSD was extremely rewarding, yet challenging. Initially, it was difficult to convince the subjects to participate in the study. A thorough explanation of the research and of the researcher's credentials was necessary to gain participation. Interestingly, the researcher found it more difficult to motivate the control group to engage in the testing procedures than the experimental group. This may have been due to the fact that the control group was not participating in any exercise activity and, therefore, it was difficult for the subjects to understand their role in the study.

The researcher was surprised with the enthusiasm and effort that the experimental group exhibited throughout the duration of the study. Comments such as, "we have been waiting for you all day," and "let's try to increase the number of stairs tonight" were quite common. In addition, the researcher's presence allowed the subjects to interact with someone who was truly interested in their problems, other than hospital staff .

The researcher believes that involvement in a purposeful activity will result in positive outcomes for the individual as long as some success is noted (this is the basis of occupational therapy and of this study). Using exercise allows the subject to achieve individualized results. The goal of this research was to reduce overall PTSD symptomatology, including anxiety and depression. However, the individuals' ultimate 
goal may be to lose weight or gain endurance. Although there was not a statistically significant change in the subject's $\mathrm{VO}_{2} \max$ in the experimental group, this does not suggest that the subjects did not experience cardiac improvements because cardiovascular function was measured using a less sensitive indirect method. The researcher found the frequency and duration of treatment for four weeks to be adequate. At the end of the four weeks, the subjects expressed a desire to engage in their own exercise regime at their individualized pace and convenience. This was a positive sign because in order to achieve the aerobic effects, one must exercise at least three to five times per week for 1560 minutes. At the beginning of the study, the subjects had similar aerobic tolerance, however, as the study progressed, some individuals worked harder and, therefore, achieved a higher level of aerobic capacity. For aerobic exercise to be effective, it must be regular (performed at least three times per week) following a specified duration (15-60 minutes of continuous movement) and the individual needs to be working at a maximum heart rate $(60-70$ percent $)$.

After the three month inpatient program the individuals must continue to exercise in order to gain the benefits. Understanding the value and meaning that an individual attaches to exercise is important in predicting whether they will follow through after hospitalization.

Occupational therapists use different types of activities depending on their facility and their patients' needs. Aerobic exercise is an activity that can be used in any setting 
with minimum equipment. In today's society, with emphasis on health and fitness, occupational therapists have an opportunity to incorporate aerobic exercise as a purposeful activity in their treatment plans.

Post Traumatic Stress Disorder is a relatively new psychiatric diagnosis that is difficult to treat because of the number of symptoms. Unfortunately, there has not been any one treatment method effective in dealing with all the symptoms, however, the use of aerobic exercise in this research showed promising results for treating the symptoms of depression and anxiety in individuals with PTSD.

\section{Recommended Changes for the Exercise Program}

It would strengthen the study and eliminate the influence of history bias if the control group were tested at the same time as the experimental group. If this were not possible then researchers could consider using two facilities simultaneously, using subjects at one as a control group and another as the experimental group.

If exercise sessions were going to be performed in a group, different subjects should have the opportunity to lead the group to allow subjects to have a feeling of self satisfaction, responsibility and leadership.

Future research using aerobic exercise should consider the following: that the length of the exercise program be extended for the duration of the subjects hospital stay 
(in this instance three months). To allow subjects to achieve an aerobic effect. Exercise should be supervised for the first four weeks to provide time for the subjects to become familiar with the treatment protocol. After the four week period, the researcher could monitor subject compliance once per week to determine those in noncompliance with specified guidelines for treatment.

\section{Recommendations for Further Research}

Aerobic exercise, as an occupational therapy intervention, has been used with a variety of populations, however, the literature review did not reveal that it has been incorporated into any regular PTSD treatment programs. Because of the positive results of this treatment with inpatient Vietnam Veterans with PTSD, it is recommended that this study be attempted with other populations who suffer from PTSD (ie. abused children, rape victims, outpatient Vietnam Veterans, hurricane victims, etc.) to study the efficacy of this treatment across patient populations. In addition, creating larger sample sizes of patients would permit generalizations. Aerobic exercise is a purposeful activity occupational therapists could use during daily treatment to decrease anxiety and depression in patients with PTSD, thereby creating a healthier person who could have a greater chance of living a more rewarding and productive life. 


\section{References}

American College of Sports Medicine. (1978). The recommended quantity and quality of exercise for developing and maintaining fitness in healthy adults. Medicine and Science in Sports, 10, vii-x.

American College of Sports Medicine. (1991). Guidelines for exercise testing and prescription (4th ed.). Philadelphia: Lea \& Febiger.

American Heart Association Committee on Exercise. (1975). Exercise testing and training of individuals with heart disease or high risk for its development. A handbook for physicians. Dallas: American Heart Association.

American Psychiatric Association. (1980). Diagnostic and statistical manual of mental disorders (3rd ed.). Washington, DC: Author.

American Psychiatric Association. (1987). Diagnostic and statistical manual of mental disorders (3rd ed rev.). Washington, DC: Author.

Beck, A. T., \& Steer, R. A. (1987). Manual for the revised Beck Depression Inventory. San Antonio,TX: The Psychological Corporation.

Beck, A. T., Epstein, N., Brown, G., \& Steer, R. A. (1988). An inventory for measuring clinical anxiety: Psychometric properties. Journal of Consulting and Clinical Psychology, 56, 893-897.

Bleich, A., Siegal, B., Garb, R., \& Lerer, B. (1986). Posttraumatic stress disorder following combat exposure: Clinical features and psychopharmacological treatment. British Journal of Psychiatry, 149, 345-369.

Blumenthal, J. A., Emery, C. F., Madden, D. J., George, L. K., Coleman, R. E., Riddle, M.W., McKee, D.C.,Reasoner, J., \& Williams, R. S. (1989).

Cardiovascular and behavior effects of aerobic exercise training in healthier older men and women. Journal of Gerontology, 44, M147- M157.

Boutcher, S. H. (1990). Aerobic fitness: Measurement and issues. Journal of sport and exercise psychology, 12, 235-247.

Brown, R. S., Ramirez, D. E., \& Taub, J. M. (1978). The prescription of exercise for depression. The Physician and Sports Medicine, 6, 34, 36-37, 40-41, 44-45. 
Brown, D. (1987). Exercise fitness and mental health. In Bouchard, Shephard, Stephens (Eds.), A concensus of current knowledge (pp. 607-626). Champaign, IL: Human Kinetics.

Buchman, B.P., Sallis, J.F., Criqui, M.H., Dimsdale, J.E. \& Kaplan, R. (1991). Physical activity, physical fitness and psychological characteristics of medical students. Journal of Psychosomatic Research, 35 (2-3), 197-208.

Charlesworth, E., \& Nathan, R.G. (1984). Stress management: A comprehensive guide to wellness New York: Atheneum.

Cooper, K.H. (1968). Aerobics New York: Evans.

Cooper, K. H. (1970). The new aerobics New York: Evans.

Cooper, K. H. (1982). The aerobics way New York: Evans.

Davidson, J., \& Nemeroff, C.B. (1989). Pharmacotherapy in post-traumatic stress disorder: Historical and clinical considerations and future directions. Psychopharmacology Bulletin, 25 (3), 422-425.

Doan, R. E., \& Scherman, A. (1987). The therapeutic effect of physical fitness on measures of personality: A literature review. Journal of Counseling and Development, 66, 28-36.

Doyne, E. J., Ossip- Klein, D. J., Bowman, E. D., Osborn, K. M., Mc DougallWilson, I. B., \& Neimeyer, R. A. (1987). Running verses weight lifting in the treatment of depression. Journal of Consulting and Clinical Psychology, 55, 748-754.

Fairbank, J. A., \& Nicholson, R. A. (1987). Theoretical and empirical issues in the treatment of post-traumatic stress disorder in Vietnam veterans. Journal of Clinical Psychology, 43 (1), 44-55.

Fidler, G. S., \& Fidler, J. W. (1978). Doing and becoming: Purposeful action and self actualization. American Journal of Occupational Therapy, 32, 305-310.

Fidler, G. S., \& Fidler, J. W. (1983). Doing and becoming: The occupational therapy experience. In G. Kielhofner (Ed.), Health through occupation: Theory and practice in occupational therapy, (pp. 267-279). Philadelphia: F. A. Davis. 
Fidler, G. S. (1991). The challenge of change to occupational therapy practice. Occupational Therapy in Mental Health, 11 (1), 1-11.

Folkins, C. H., \& Sime, W. E. (1981). Physical fitness training and mental health. American Psychologist, 36, 373-389.

Frazian, B. W. (1985). Tidal surge and private practice: The historic eighties. Private Practice in Occupational Therapy, 2 (2), 7-12.

Fremont, J., \& Craighead, L.W. (1984). Aerobic exercise and cognitive therapy for mild/moderate depression. Presented at the Association for Advancement of Behavior Therapy, Philadelphia, PA.

Gibson, D. (1989). The challenge of adaptation: Shaping service delivery to meet changing needs. Hospital and Community Psychiatry, 41, 267-269.

Goldwater, B. C., \& Collins, M. L. (1985). Psychologic effects of cardiovascular conditioning: A controlled experiment. Psychosomatic Medicine, 47, 174-181.

Griest, J. H., Klein, R. R., Eishens, J., Faris, A. J., Gurman, \& Morgan, W. P. (1979). Running as a treatment for depression. Comprehensive Psychiatry, 53, 20-41.

Grinker, R. R., \& Spiegal, J. P. (1945). Men under stress. Philadelphia: Blackington.

Hales, R.E., \& Travis, T. W. (1987). Exercise as a treatment option for anxiety and depressive disorders. Military Medicine, 152 (6), 299-302.

Hammarberg, M. (1992). Penn inventory for posttraumatic stress disorder: Psychometric properties. Psychological Assessment, 4 (1), 67-76.

Hammer, W. M., \& Wilmore, J. H. (1973). An exploratory investigation in personality measures and physiological alterations during a ten-week jogging program. Journal of Sports Medicine, 13, 238-247.

Hannaford, C. P., Harrell, E.H., \& Cox, K. (1988). Psychological effects of a running program on depression and anxiety in a psychiatric population. Psychological Record, 38, 37-48.

Harmand, J., Starkey, T., \& Ashlock, 1. (1987). A follow-up of Miami model graduates 6-12 months afterward, Vet Center Voice, 8 (4), 8-9. 
Hayden, R. M., \& Allen, G. J. (1984). Relationship between aerobic exercise, anxiety, and depression: Convergent validation by knowledgeable informants. Journal of Sports Medicine and Physical Fitness, 24, 69-74.

Hughes, J. R. (1984). Psychological effects of habitual aerobic exercise: A critical review. Preventive Medicine, 13, 66-78.

International Society of Sport Psychology Position Statement. (1992). Physical activity and psychological benefits. The Physician and Sports Medicine, 20 (10), 179-184.

Keane, T. M., Wolfe, J., \& Taylor, K. (1987). Posttraumatic stress disorder: Evidence for diagnostic validity and methods of psychological assessment. Journal of Clinical Psychology, 43 (1), 32-43.

Kulka, R. A., Fairbank, J. A., Hough, R. L., Jordan, B. K., Marmar, C. R., \& Weiss, D. W. (1990). Trauma and the Vietnam generations: Findings from the national Vietnam veterans readjustment study. New York: Brunner Mazel.

Long, B. C., \& Haney, C. J. (1988). Coping strategies for working women: Aerobic exercise and relaxation interventions. Behavior Therapy, 19, 75-83.

Ludwig, F. M. (1988). Six perspectives on theory for the practice of occupational therapy. Maryland: Aspen Publishers.

Maloney, J. P., Cheney, R., Spring, W., \& Kanusky, J. (1986). The physiologic and psychological effects of a 5 week and a 16 week physical fitness program. Military Medicine, 151, 426-433.

Martinsen, E. W., Hoffart, A., Solberg, O. (1989). Comparing aerobic with non-aerobic forms of exercise in the treatment of clinical depression: A randomized trial. Comprehensive Psychiatry, 30 (4), July/Aug, 324-331.

McCann, I. L., \& Holmes, D. S. (1984). Influence of aerobic exercise on depression. Journal of Personality and Social Psychology, 46, 1142-1147.

McCardle, W. (1991). Exercise Physiology. Pennsylvania: Lea \& Febiger.

Mellman, T. A., Randolph, C. A., Mintzer-Brawman, O., Flores, L.P., \& Milanes, F. J. (1992). Phenomenology and course of psychiatric disorders associated with combat- related post traumatic stress disorder. American Journal of Psychiatry, 149, (11) 1568- 1574. 
Morgan, W. P. \& Goldston, S. E., (Eds). (1987). Exercise and mental health. Washington, DC: Hemisphere.

Mosey, A. C. (1981). Occupational therapy: Configuration of a profession. New York: Raven Press.

Myers, D. (1986). Psychology. New York: Worth Publishers.

Peterson, K. C., Prout, M. F., \& Schwartz, R. A. (1991). Post- traumatic stress disorder: A clinicians guide. New York \& London: Plenum Press.

Rape, R. N. (1987). Running and depression. Perceptual and Motor Skills, $64,1301-1310$.

Robinson, A. M., \& Avollone, J. (1990). Occupational therapy in acute inpatient psychiatry: An activities health approach. American Journal of Occupational Therapy, 44, 809-814.

Scurfield, R. M., Kenderline, S. K., \& Pollard, R. J. (1990). Inpatient treatment for war-related post-traumatic stress disorder: Initial findings on a longer-term outcome study. Journal of Traumatic Stress, 3 (2), 185-201.

Silver, S. M., \& Iacono, C. V. (1984). Factor analytic support for DSM-III's PTSD for Vietnam veterans. Journal of Clinical Psychology, 40, 5-14.

Sime, W. E. (1984). Psychological benefits of exercise training in the healthy individual. In J. D. Matarazzo, S. M. Weiss, J. A. Herd, \& N. E. Miller (Eds.). Behavioral health: A handbook of health enhancement and disease prevention (pp. 488-508). New York: John Wiley.

Simons, A. D., McGowen, C. R., Epstein, L. H., \& Kupfer, D. J. (1985). Exercise as a treatment for depression: An update. Clinical Psychology Review, 5, 553-568.

Solomon, S. D., Gerrity, E. T., \& Muff, A. M. (1992). Efficacy of treatments for posttraumatic stress disorder. Journal of American Medical Association, 268 (5), 633-638.

Thompson, J. K., \& Martin, J. E. (19840. Exercise in health modification: Assessments and training guidelines. Behavior Therapist, 7, 5-8. 
APPENDIX A 
Name

Dave

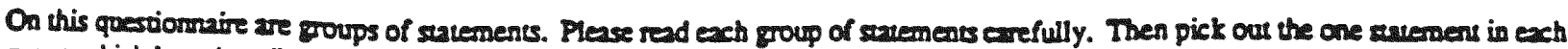
group which best describes the way you have been feeling during the PAST WEEX, DNCUDDNG TODAY! Circle the aumber beside

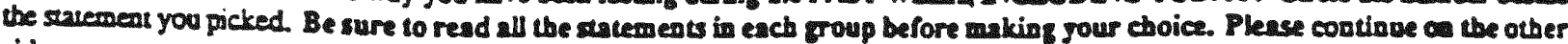
side

1 - I dor'i feel mueb differear thros mont aber people my age

1 I foel socowhat differess tho mosa ocher people ay age

2 Ifeel so difrerens thas most aber people ay age thal choose prexy cerefilly who I"I be with and when.

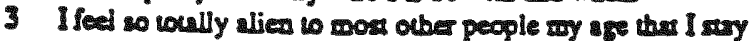
a way from ill of them at all cons.

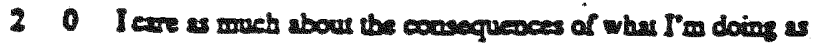
most abe people.

1 I care less abour the consequesces of whu l"m doing then nas acher peopice.

2 I care nauch less sbout the consequexes of what I'm doing then most ocher people.

3 Ofver I lhick "Let che consequesces be dumed!" because I doa'l care abous them a all.

3 When I was to do something for exjoymens I cas find wemeone 10 join the if I was 10

1 T able wo do romeching for enjoyment ever when I cas's find someone to join me.

2 I lose interest in doins thing for enjoyment whes there's do ane to join the

3 I have ao interent in doing anyrhing for exjoymens at all

4. Irecly feel jurspy ex uptight.

1 I notimes foel jumpy and upughes

2 Iofter leel jurnoy or uptighe

3 If feel jumpy or uptighs all the time.

5 I I trow someone nearby who really undersands me.

1 Im not concented whether anyone searby really underrands me

2 In worried because no one searby really undersands we.

3 I"m very worried beeause no one pearby undersands ms a all

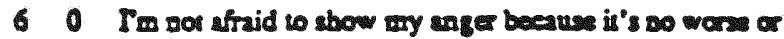
bener than anyone else'2

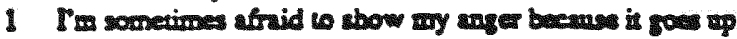
quicker than ouber people's

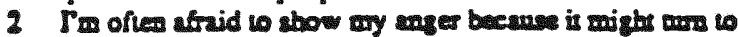
riolener.

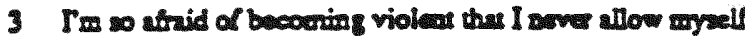
- thow ery anger as all

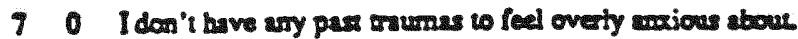

1 When something reninds tre of ury pass trumus I feed anjous but can volerste is

2 When someching reminds me of my pas tramas I feel very anxious and mus really make an efor wo volenatu is

3 When somethins reninds co of my peas crumas if foof so majous i en herdy and is and bave so wrys bo werus is

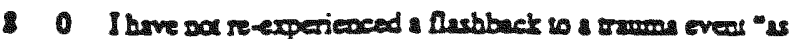
if I wase bere again"

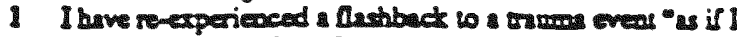
were there squin" for a few mimuses or lexs.

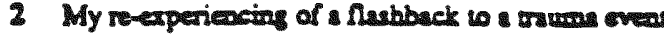
cometiones lass the beater part of an bour.

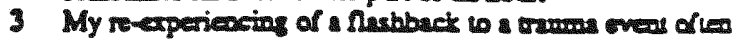
Less for an bour of more.

- I an less earily discrieted then ever.

I I aco as eusily diruncied as sver.

2 I an wore ensily distreced thas eves.

3 I feel dircreted ill the time

10 - My pirimal life provides mare meanion tho it esed w.

1 My epiriaral life provides abous as much meaning as is uned io.

2 My spirimul tif provides les meaning than is and to.

3 I doo'l care abour ay mpirianal lise

11 - I ean concentrinte becter than ever.

1 I can concerstus about as well as ever.

2 I can'r concontrat as well at I used $u$.

3 I con'i cancentrits as all

12 - Tv told a friend af furily mernber abous the imporans pars of my mon troumatic experiences.

1 I've had wo be careful in eboosiog the pars of try tras. mutis experiences to tell triendis a farily mermbers.

2 Some purs of wy crumuie experience ene 20 burd to

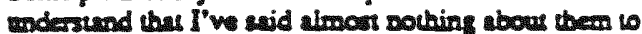
exyose

3 No one could ponxibly understand the remuntic experi. exces l've had to live with

13 - I generally doo's have zi ghwores.

1 My aighunare erese toubling than they were.

2 My nighurarses are jus as croubling as they were.

3 My wifhurare ere mars troublin thas they were.

14 I I don'I foel conhused about my life.

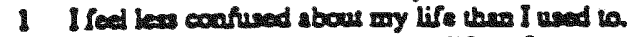

2 I feel jast as cocfued abour my life as I and io.

3 I feel more coafued abour my life thas I used to.

15 - I loow myelif beare than I med to.

I I loow myelf abour as well an I ased in

2 I doo'i bow ayself as well as I used uo.

3 Ifed like I doa'I boow who I urs at all.

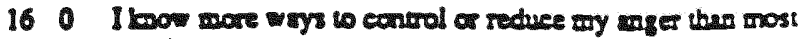
people.

1 I bow about as many ways to conerol ar rechee my uger as mant people.

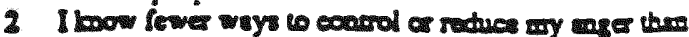
mon people.

3 I bow of no wys wo control of reduce wy enger. 
17 Itave aca experienced anjor trama in my life.

1 I hve eppriesced oce or mare zrumes of limiled inteasity.

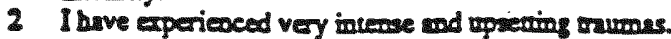

3 Do trumas I bave experienced were so iniense thas mecories of then intrude ca my mind wibous wrming.

18 Tre bes ble to shape things wow ataining many of my coals.

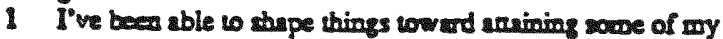
sols.

2 My gals ares's clexs.

3 I doa's boow bow to shape things wowerd my gave.

190 I w able to focus try mind wod concenarate co the thet at had regardless of unwanted bouthis.

1 Whes worented thoughts intrude an my mind I" $\mathrm{m}$ able to recogrixe then briefly and thes refocus ury mind an the tos as arod.

2 Im trins herd time coping with urated tboughs and don'l bow bow to refocus ny mind oo be ust as band.

3 Tu neve be able to cope vith uswaned thoughe

20 I an achievins most of the things I wane.

1 I am achieving many of the thines I wan

2 I an actieving some of the thirss I wan

3 I wo actieving few of the things I wat

210 I leep as well us uนม.

1 I don't deep as well as urul.

2 I whe up more trequenty or extier the wal and bave diriculty gecuing back wo sleep.

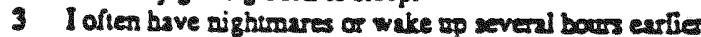
than urual and canoor get back io sleep.

22 I don's hrve rouble remembering things I thould kow.

1 I urve les trouble thas I used to remembering things I should know.

2 I buve about the same trouble as I nsed to remembering things I hould bnow.

3 I hrve tnore trouble then I used to remenberize things I bould know.

230 My gowls are elearer than they were.

1 My gals are as cleas as they were.

2 My gosts are not is elear a tbey were.

3 I don's bow whas any goals are.

24 It usully able to le bad mexaries fade froxs ay mind.

1 Sometimes bad menary comes bect 10 bul I can modif it replece it, or as is uide.

2 When bad memories inurude ca my mind I ea'? seex to ges thes out

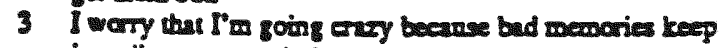
incudirs on my miod.

25 Usully I feel understood by obers.

1 Sometimes I don'l feel understood by whers.

2 Mos of the tione I don'l feel wadernood by ahers.

3 No oos andertads me all

26 I hve not los anythisg or anyon deas un we

1. I have Fieved for those I've lost end can now go con

2 I haven'i Inished grieving for those I've loce

3 The pain of ary loss is so great tha I can't crieve and don't bow bow 10 ger sured.

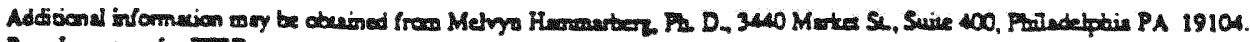
Pans trventory for PTSD assem mens.

O1990 Melyy Hammarters. PH. D.

MINZS. 
APPENDIX B 
Below is a list of common symotoms of anxiely. Please carefully read each item in the list. Indicate how much you have been bothered by each symptom during the PAST WEEK. INCLUDING TODAY, by placing an $X$ in the corresponding space in the column nexi to aach sympiom

1. Numbness or tingling.

2. Feeling hot.

3. Wobbliness in legs.

4. Unable to relax.

5. Fear of the worst happening.

6. Dizzy of lightheaded.

7. Hean pounding or racing.

8. Unsteady.

9. Temified.

10. Nervous.

11. Feelings of choking.

12. Hands trembling.

13. Shaky.

14. Fear of losing control.

15. Difficulty breathing.

16. Fear of dying.

17. Scared.

18. Indigestion or discomfon in uhumen.

19. Faint.

2n. Face flushed.

21. Sweating (not due to heid).
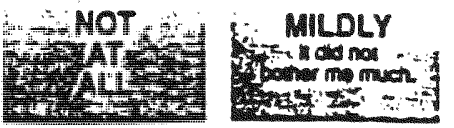

MODEAATELY

- was un

2.0.

SEVERELY

ortusente

and

24.

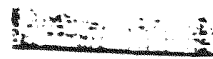

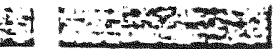

$4 x+2+1$

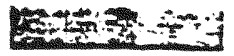

$5-\div-74$

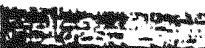

$=1$

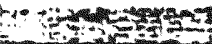

58: $: 7:-7 \div 3$

मु०

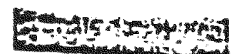

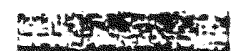

-

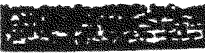

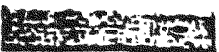

4.

$+3$

$x=-2+2$

Estres

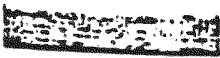

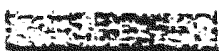

27.: $:-27$

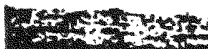

$x^{2}-2 y-3$

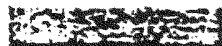
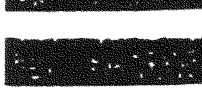

$1+1+2 x+3$

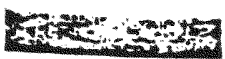

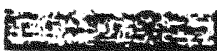

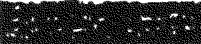

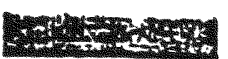

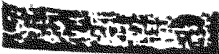

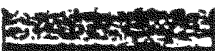

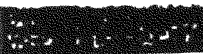

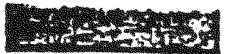

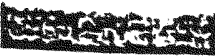

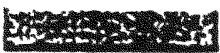

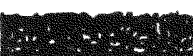

-7x $x^{2}+3 x^{2}$

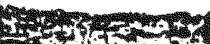

Rist3 523

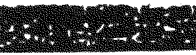

62.

tow 3

(x)

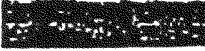

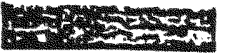

2 23

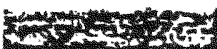

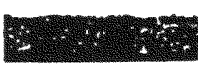

\section{4xis}

srasp

845

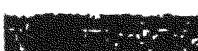

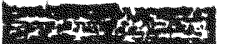

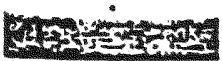

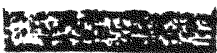

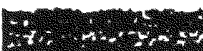

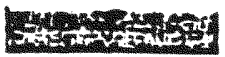

Laxtays

Fion

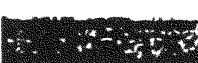

bers

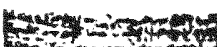

4.2.

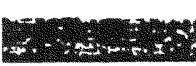

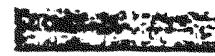

$2: 2 x+2$

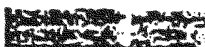

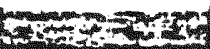

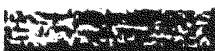

5. $.30 \pm x$

brist-7x:

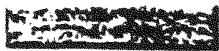

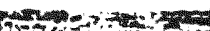

Esistest

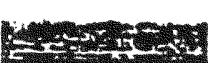

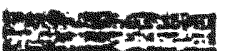

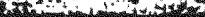

20

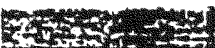

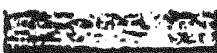

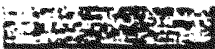

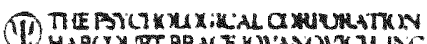

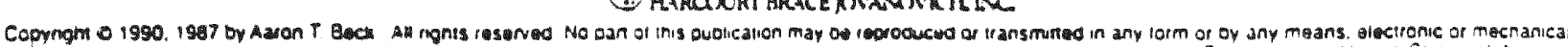

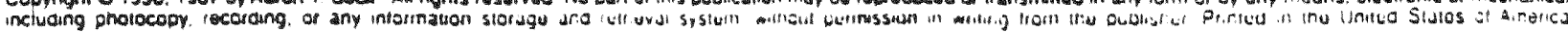
Q i it 2 a C OE

$89015 \times 25$ 
APPENDIX C 
Narre:

Marital Status:

Age:

Sex:

Occupation:

Education:

This questionnaire consists of 21 groups of statements. After reading each group of statements caref ully, circle the number $(0,1,2$ or 3$)$ next to the one statement in each group which best describes the way you have been feeling the past week, including today. If several statements within a group seem to apply equally well. circle each one. Be sure to read all the statements in each group belore making your choice.

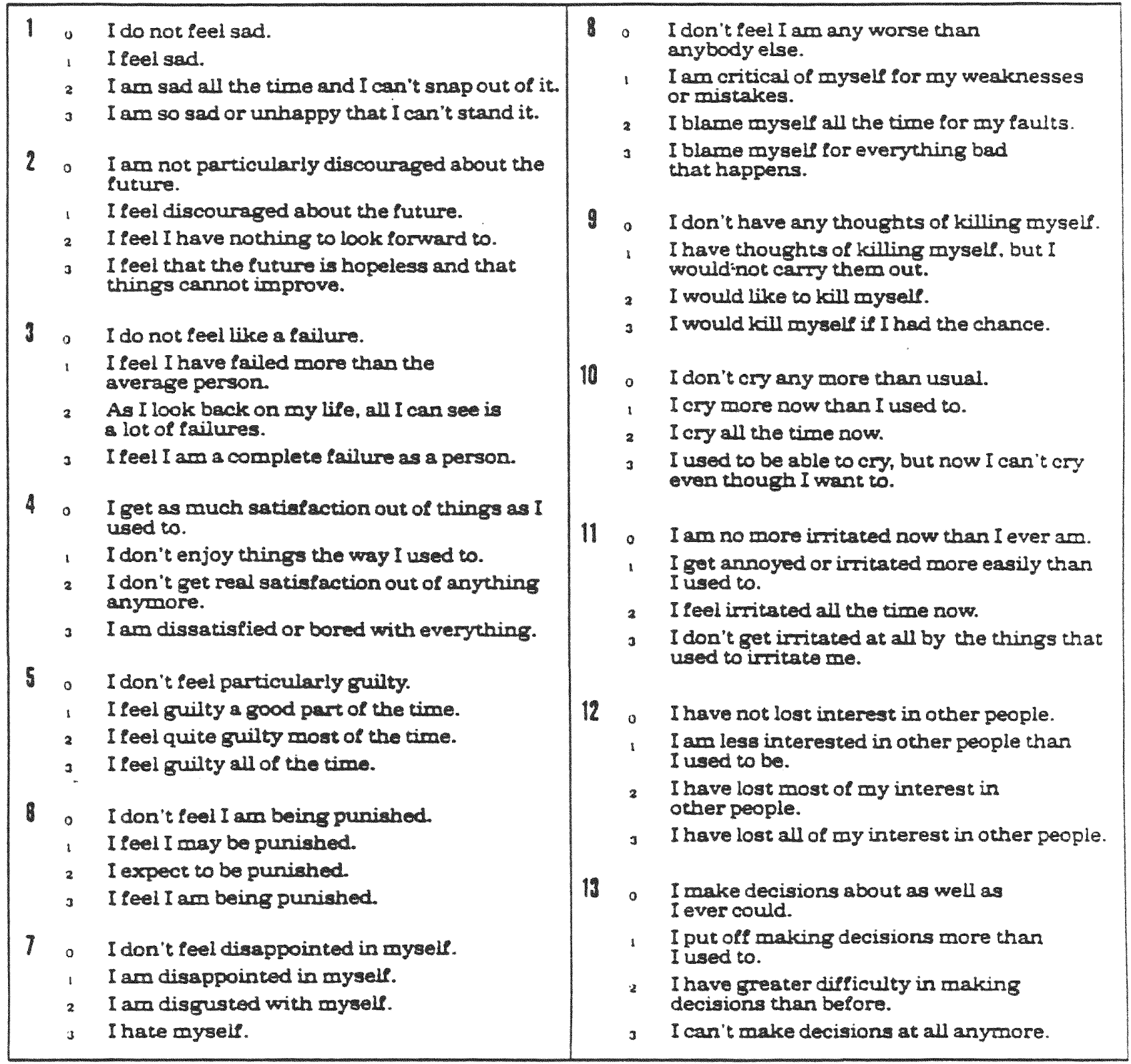




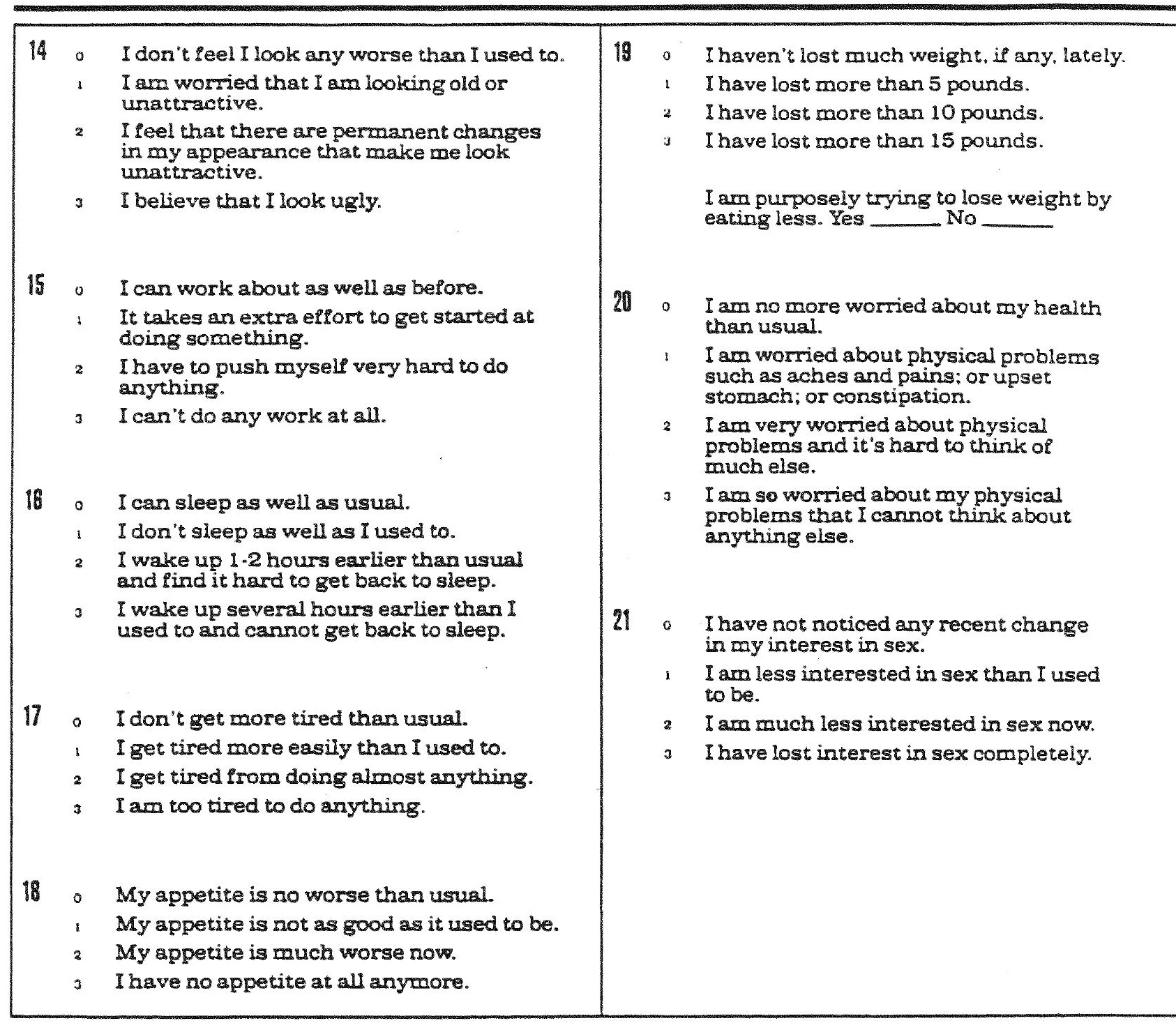

Subtotal Page 2

Subtotal Page 1

Total Score 
APPENDIX D 


\section{AEROBIC FITNESS CHART}

\begin{tabular}{|c|c|c|c|}
\hline Week 1 & Type of Exercise & Length of Time & Heart Rate \\
\hline \multicolumn{4}{|l|}{ Day 1} \\
\hline \multicolumn{4}{|l|}{ Day 2} \\
\hline \multicolumn{4}{|l|}{ Day 3} \\
\hline Week 2 & Type of Exercise & Length of Time & Heart Rate \\
\hline \multicolumn{4}{|l|}{ Day 1} \\
\hline \multicolumn{4}{|l|}{ Day 2} \\
\hline \multicolumn{4}{|l|}{ Day 3} \\
\hline Week 3 & Type of Exercise & Length of Time & Heart Rate \\
\hline \multicolumn{4}{|l|}{ Day 1} \\
\hline \multicolumn{4}{|l|}{ Day 2} \\
\hline \multicolumn{4}{|l|}{ Day 3} \\
\hline Week 4 & Type of Exercise & Length of Time & Heart Rate \\
\hline \multicolumn{4}{|l|}{ Day 1} \\
\hline \multicolumn{4}{|l|}{ Day 2} \\
\hline Day 3 & & & \\
\hline & & & \\
\hline
\end{tabular}


APPENDIX E 


\section{STEP TEST APPROVAL}

is physically able to participate in the three-minute step test

for the research titled: "The Use of Aerobic Exercise as an Occupational Therapy Intervention for Post Traumatic Stress Disorder Patients."

Dr. Mellman, M.D.

Post Traumatic Stress Disorder Unit, Veterans Affairs Hospital, Miami, FL 
APPENDIX F 


\section{STEP TEST and AEROBIC EXERCISE APPROVAL}

is physically able to participate in the three-minute step test and aerobic exercise for the research titled: "The Use of Aerobic Exercise as an Occupational Therapy Intervention for Post Traumatic Stress Disorder Patients."

Dr. Mellman, M.D.

Post Traumatic Stress Disorder Unit, Veterans Affairs Hospital, Miami, FL 
APPENDIX G 
Subject Narre:

Date:

Title of Study: The Use of Aerobic Exercise as an Occupational Therapy Treatment Intervention for Post Tramatic Stress Disorder Patients.

Principal Investigator: Dr. Gary Rutcher, Ph.D

VAMC:

Miami, EL

PURPOSE OF STUDY AND HOW LONG IT WLL LAST: You are being asked to participate in a research study on exercise and Post Traumatic Stress Disorder (PTSD). PTSD is a type of mental disorder in which people who have been in a stressful situation (such as combat) may have emotional problems. The goal of this study is to better understand the effects of exercise on your symptoms.

Some people who have had very stressful or threatening experiences may get PTSD. For many people, PTSD includes feelings of anxiety and depression. Past research on exercise has shown that it can be helpful in reducing many of these symptoms.

Your taking part in this study depends on your physical condition. A medical doctor's approval will be needed. This study will last four weeks.

DESCRIPTION OF THE STUDY INCLUDING PROCEDURES TO BE USED: Approximately 32 subjects (VA patients) will participate in this study. At the beginning of the study, you will first be asked to perform a "Step Test." This involves stepping up and down on a imitation step for three minutes and then having your heart rate measured. You will be given the Step Test on the first and the last day of the four-week study period. To see whether the exercise is having any effect, you will be asked to fill out three short questionnaires at the beginning and at the end of the study (four weeks later).

DESCRIPTION OF ANY PROCEDURES THAT MAY RESULT IN DISCOMFORT OR INCONVENIENCE: While no discomfor is expected from your participation in this study, it is not possible to guarantee that you won't feel the discomfort that might come with regular exercise (such as muscle soreness and tiredness).

EXPECTED RISKS OF STUDY: While no risks are expected from participating in this study, there is no way to completely rule out possible discomfort from regular exercise (muscle soreness and tiredness). To reduce any possible risk to yourself, your taking part in this study depends on your physical condition. A medical doctor's approval will be needed. 


\begin{tabular}{|c|c|}
\hline 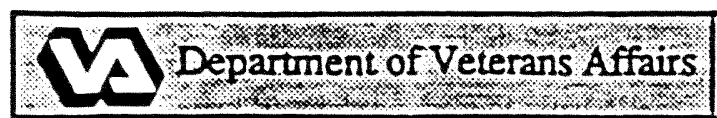 & $\begin{array}{l}\text { VA Research Consent Form } \\
\text { Comimation Page } 2 \text { of } 2\end{array}$ \\
\hline
\end{tabular}

Subject Name:

Date: The Use of Aerobic Exercise as an Occupational Therapy Treatment
Title of Study: Intervention for Post Traumatic Stress Disorder Patients.

Principal Investigator: Dr. Gary Kutcher, Ph.D VAMC: Miami, FL

EXPECTED BENEFITS OF STUDY: No benefit can be promised to you from your participation in this study. Others may benefit from the information gathered from your participation. The results from this study can be given to you, if you wish.

OTHER TREATMENT(S) AVAILABLE: The other treatments available to you include those in the PTSD program. These treatments include: occupational therapy, music therapy, recreational therapy, combat group and individual therapy.

USE OF RESEARCH RESULTS: Your name and other information about you will not be used without your permission. The results of all participants, as a group, will be the only information used in the study. You will be told, and given in writing, any new information that might affect your decision to be in the study. You may ask any questions you want to about the study and you can refuse to be in the study or stop being in the study at any time. If you do refuse or stop being in the study, the care you are entitled to at the VA will not be affected in any way. If you have any questions about your legal rights or whether you can receive medical care because of problems caused by being in the research study, you can call the Chief of Medical Administration or his representative at extension 3051 . 
Subject Name:

Dare:

Title of Studythe Use of Aerobic Exercise as an Occupational Therapy Treatment Intervention for Post Traumatic Stress Disorder Patien

Principal Investigator:

$$
\text { Dr. Gary Rutcher, Ph.D }
$$

VAMC

Research Subjects Rights: I have read or have had read to me all of the above. Dr.Kutcher has explained the study to me and answered all of my questions. I hilve been told of the risks or discomforts and possible benefits of the study. I have been told of other choices of treament available to me.

I understand that I do not have to take part in this study, and my refusal to participare will involve no penalty or loss of rights to which I am entitled. I may withdraw from the study at any time without penalty or loss of VA or other benefits to which I am entitled.

The results of this study may be published, but my records will not be revealed unless required by law.

In case there are medical problems or questions, I have been told I can call Dr. Kutche r at $324-4455$ ext .3652 during the day and Dr. Kutcher at $324-4455$ after hours. If any medical problems occur in connection with this study the VA will provide emergency care.

I understand my rights as a research subject, and I voluntarily consent to participare in this study. I understand what the study is about and how and why it is being done. I will receive a signed copy of this consent form.

Subject's Signarure

Signarure of Subject's Representative *

Signarure of Wimess

Signarure of Investigator

* Only required if subjects not competent.

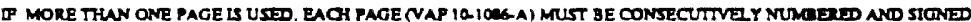

Dare

Subject's Representatives

Witness (print) 
APPENDIX H 
Subject Narre:

Dare:

Tide of Study: Use of Aerobic Exercise as an Occupational Therapy Tr
Intervention for Post Traumatic Stress Disorder Patients.

Principal Investigaror: Dr. Gary Rutcher, Ph.D VAMC: Miami, FL

PURPOSE OF STUDY AND HOW LONG IT WILL LAST: You are being asked to participate in a research study on exercise and Post Traumatic Stress Disorder (PTSD). PTSD is a type of mental disorder in which people who have been in a stressful situation (such as combat) may have emotional problems. The goal of this study is to better understand the effects of exercise on your symptoms.

Some people who have had very stressful or threatening experiences may get PTSD. For many people, PTSD includes feelings of anxiety and depression. Past research on exercise has shown that it can be helpful in reducing many of these symptoms.

Your taking part in this study depends on your physical condition. A medical doctor's approval will be needed. This study will last four weeks.

DESCRIPTION OF THE STUDY INCLUDING PROCEDURES TO BE USED: APproximately 32 subjects (VA patients) will participate in this study. During this study you will be asked to exercise three times a week for four weeks. Each exercise session will include a five minute stretching period, then $15-25$ minutes of exercise (your choice of walking or stair climbing), then five minutes of cool-down. During this study you will be taught how to monitor your heart-rate to be sure that you are exercising safely.

At the beginning of the study, you will first be asked to perform a "Step Test." This involves stepping up and down on a imitation step for three minutes and then having your heart rate measured. You will be given the Step Test on the first and the last day of the four-week study period. To see whether the exercise is having any effect, you will be asked to fill out three short questionnaires at the beginning and at the end of the study (four weeks later).

DESCRIPTION OF ANY PROCEDURES THAT MAY RESULT IN DISCOMFORT OR INCONVENIENCE: While no discomfor is expected from your participation in this study, it is not

Subjects Identification (ID. plare or give name-lasc, first, middle) possible to guarantee that you won't feel the discomfor that might come with regular exercise (such as muscle soreness and tiredness). 
Subject Name:

Date:

Tide of Study: The Use of Aerobic Exercise as an Occupational Therapy Treatment Incervention for Post Traumatic Stress Disorder Patients.

Principal Investigaror: Dr. Gary Kutcher, Ph.D VAMC: Miami, FL

EXPECTED RISKS OF STUDY: While no risks are expected from participating in this study, there is no way to completely rule out possible discomfort from regular exercise (muscle soreness and tiredness). To reduce any possible risk to yourself, your taking part in this study depends on your physical condition. A medical dostor's approval will be needed.

EXPECTED BENEFTTS OF STUDY: No benefit can be promised to you from your participarion in this study. Others may benefi! from the information gathered from your participation. The resuits from this study can be given to you, if you wish.

OTHER TREATMENTIS) AVAMABLE: The other treaments available to you include those in the PTSD program. These treatment include: occupational therapy, music therapy, recreational therapy, combat group and individual therapy.

USE OF RESEARCH RESULTS: Your name and other information about you will not be used without your permission. The results of all participants, as a group, will be the only information used in the study. You will be told, and given in writing, any new information that might affect your decision to be in the study. You may ask any questions you want to about the study and you can refuse to be in the study or stop being in the study at any time. If you do refuse or stop being in the study, the care you are entitled to at the VA will not be affected in any way. If you have any questions about your legal rights or whether you can receive medical care because of problems caused by being in the research study, you can call the Chief of Medical Administration or his representative at extension 3051. 
Subject Name:

Date:

Title of Study? Uhe Use of Aerobic Exercise as an Occupational Therapy

Treatment Intervention for Post Traumatic Stress Disorder Patien

Principal Investigaror:

Dr. Gary Rutcher, Ph. D

VAMC:

Research Subjects Rights: I have read or have had read to me all of the above. Dr.Kutcher has explained the study to me and answered all of my questions. I have been told of the risks or discomforts and possible benefits of the study. I have been told of other choices of treament available to me.

I understand that I do not have to take part in this sudy, and my refusal to participare will involve no penalty or loss of rights to which I am entiled. I may withdraw from the study at any time without penalty or loss of VA or other benefits to which I am entiuled.

The results of this study may be published, but my records will not be revealed unless required by law.

In case there are medical problems or questions, I have been told I can call Dr. Ku t che af $324-4455$ ext 3652 during the day and Dr. Kutcher at $324-4455$ after hours. If any medical problems occur in connection with this srudy the VA will provide emergency care.

I understand my rights as a research subject, and I voluntarily consent to participare in this study. I understand what the study is about and how and why it is being done. I will receive a signed copy of this consent form.

Subject's Signarure

Signarure of Subject's Representarive *

Signarure of Winess

Signarure of Investigator

* Only required if subjects not comperent.

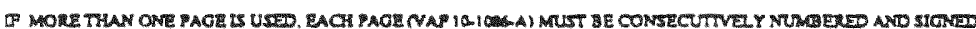

Dare

Subject's Representarives

Witness (print) 
APPENDIX I 


\section{Diagnostic Criteria for Post Traumatic Stress Disorder}

A. The person has experienced an event that is outside the range of usual human experienced and that would be markedly distressing to almost anyone, e.g., serious threat to one's life or physical integrity; serious threat or harm to ones children, spouse, or other close relatives and friends; sudden destruction of one's home or community; or seeing another person who has recently been or is being, seriously injured or killed as the result of an accident or physical violence.

B. The traumatic event is persistently reexperienced in at least one of the following ways:

1. recurrent and intrusive distressing recollections of the event (in young children, repetitive play in which themes or aspects of the trauma are expressed)

2. recurrent distressing dreams of the event

3. sudden acting or feeling as if the traumatic event were recurring (includes a sense of reliving the experience, illusions, hallucinations, and dissociative [flashback] episodes, even those that occur upon awakening or when intoxicated)

4. intense psychological distress at exposure to events that symbolize or resemble an aspect of the traumatic event, including anniversaries of the trauma

C. Persistent avoidance of stimuli associated with the trauma or numbing of general responsiveness (not present before the trauma), as indicated by at least three of the following:

1. efforts to avoid thoughts or feelings associated with the trauma

2. efforts to avoid activities or situations that arouse recollections of the trauma

3. inability to recall an important aspect if the trauma (psychogenic amnesia)

4. markedly diminished interest in significant activities (in young children, loss of recently acquired developmental skills such as toilet training or language skills)

5. feeling of detachment or estrangement from others

6. restricted range of affect, e.g., unable to have loving feelings

7. sense of foreshortened future, e.g., does not expect to have a career, marriage, or children, or a long life

D. Persistent symptoms of increased arousal (not present before the trauma), as indicated by at least two of the following:

1. difficultly falling or staying asleep

2. irritability or outbursts of anger

3. difficulty concentrating

4. hypervigilance

5. exaggerated startle response

6. physiologic reactivity upon exposure to events that symbolize or resemble an aspect of the traumatic event (e.g., a woman who was raped in an elevator breaks out in a sweat when entering any elevator)

E. Duration of the disturbance (symptoms in B,C, and D) of at least one month 